\title{
Market Structure and Partnership Levels in Air-Rail Cooperation
}

\author{
Changmin Jiang ${ }^{\text {a,d*, Tiziana D’Alfonso }}{ }^{\text {b,d }}$, Yulai Wan ${ }^{\mathrm{c}, \mathrm{d}}$ \\ ${ }^{a}$ Asper School of Business, University of Manitoba, Winnipeg, MB R3T 2N2, Canada \\ b Department of Computer, Control and Management Engineering “Antonio Ruberti", \\ Sapienza Università di Roma, Via Ariosto 25 - 00185 Rome, Italy \\ ${ }^{c}$ Department of Logistics and Maritime Studies, Hong Kong Polytechnic University, \\ Hung Hom, Kowloon, Hong Kong \\ d Transport Institute, University of Manitoba, Winnipeg, MB R3T 2N2, Canada
}

Jan 2017

\begin{abstract}
:
We build a theoretical model to study different air-rail cooperation scenarios. We investigate two possible air-rail partnerships between a rail operator and either a domestic airline or a foreign airline. When a partnership is formed, an investment to improve the airrail connecting service is allowed at a cost before the service is launched. We find that the cooperation level, the equilibrium partnership scenarios when air-rail cooperation is exclusive or non-exclusive, as well as the comparisons of social welfare under different partnership scenarios, all depend on the pre-investment quality of air-rail service compared with the quality of air-air service.
\end{abstract}

Keywords: Airline, Rail, Cooperation, Domestic partnership, International partnership

*Corresponding author

E-mail: changmin.jiang@umanitoba.ca 


\section{Introduction}

In recent years, high-speed rail (HSR) has become a major competitor and substitute for air transport (Yang and Zhang, 2012; Jiang and Zhang, 2016; Jiang and Li, 2016). On shorthaul routes, airlines usually lose ground to HSR, being either forced out of the market totally or into big cutbacks (e.g., Park and Ha, 2006; Barròn et al., 2009; Dobruszkes, 2011; Fu et al., 2012; 2014; Wan et al., 2016). However, air transport has incomparable advantages in long-distance travel and extensive networks. Due to this difference in advantages as well as the hub-and-spoke network adopted by most major airlines, HSR can complement air transport by connecting between airports and nearby cities, and hence the potential for air-rail cooperation exists. Under hub-and-spoke operation, passengers complete one journey from the origin airport to the destination airport by taking two flights ("legs") connecting at a hub airport. With HSR, however, both these legs need not be air flights: on legs where HSR service is comparable with flights in terms of (total) journey time and cost, HSR service may be used in combination with a flight in one journey. ${ }^{1}$ Such air-rail cooperation may be viewed as a special type of "code sharing" - i.e., two airlines cooperate to offer a hub-and-spoke operation with each offering one leg of a trip (and the non-operating carrier is allowed to put its code on the operating airline's flight number) which is common in the airline industry (e.g., Oum et al., 1996; Brueckner, 2001; Ito and Lee, 2007; Gayle, 2008).

There are several driving forces behind the formation of air-rail cooperation. First, some short-haul flights are unprofitable to operate but indispensable for the airlines' network. Substituting these flights with train trips allows the airlines to maintain their networks and, at the same time, focus on operating the more profitable long-distance flights (Givoni and Banister, 2006). Second, it is possible that some hub airports are under serious capacity constraint. By forming intermodal cooperation, the airlines can divert part of the short-haul traffic to the rail (Givoni and Banister, 2006; Janic, 2011; Jiang and Zhang, 2014; Avenali et al. 2016). Third, policy makers are in favor of intermodal cooperation because it is generally believed that substituting air traffic with rail traffic can alleviate the impacts on

\footnotetext{
${ }^{1}$ In fact, the air-rail cooperation is not confined to high-speed rail. There are also cases of such intermodal partnerships in countries without real HSR, such as US and Canada.
} 
the environment (D'Alfonso et al., 2015, 2016). Fourth, due to freedom of the air, foreign airlines are usually excluded from, or seriously constrained in, domestic routes. With the help of air-rail cooperation, these airlines can significantly increase their market presence and avoid being undercut by the powerful national airlines (Chiambaretto and Decker, 2012). Besides, as suggested by Chiambaretto (2015) with a two-dimension framework of resource dependence and power balance, foreign airlines should proactively redesign their market boundaries to find new partners, i.e., to substitute the traditional airline alliance with air-rail intermodal cooperation, so as to avoid being undercut by the powerful national airlines. Airlines are usually the initiators of such cooperation schemes, but in some cases both the airline and the rail operator, at times even the hub airport, are actively involved in the partnership (e.g., the AIRail case in Germany). ${ }^{2}$

All of the existing analytical studies on air-rail intermodal cooperation adopt a hidden assumption that there is only one type of cooperation (e.g., Givoni and Banister, 2006; Socorro and Viecens, 2013; Jiang and Zhang, 2014; Xia and Zhang, 2016a; 2016b). However, in reality there is substantial diversity among the existing air-rail cooperation cases. ${ }^{3}$ This paper focuses on two interesting aspects of this diversity that have not yet been extensively explored. On the one hand, the rail operator might cooperate with different types of airlines. Some cooperation cases are between domestic airlines and rail operators, such as in China, Portugal, Switzerland, and USA; while other cases involve foreign airlines, such as in Italy and Spain. In countries like France, Germany, UK, as well as Canada, both situations exist simultaneously. On the other hand, the levels of cooperation in different cases can be diverse. Some cooperation is basic and nothing more than an emergency back-up strategy for extreme cases. For example, there is a re-protection agreement between Air Canada and VIA Rail, which will only be triggered under major delay or cancellation disruptions from the air sector. Some cooperation is very advanced with features like integrated ticketing, dedicated carriage, coordinated scheduling, and baggage push. The most renowned example of such high cooperation level is the AIRail service provided by Lufthansa and Deutsche Bahn at Frankfurt Airport. More partnerships

\footnotetext{
${ }^{2}$ As noted by Chiambaretto and Decker (2012), "the rail operator typically charges the airline for the transport services, and the airline then determines whether, and how, to reflect this cost in the price of the entire trip". ${ }^{3}$ Please see Appendix A for a summary of the existing cases of air-rail cooperation.
} 
have a cooperation level that is in between these two extremes. In particular, for these services, ticketing is usually integrated, but baggage push and dedicated train compartments are seldom available. Such cases abound across Europe and Asia (in Taiwan, as well as Mainland China). More interestingly, some anecdotes seem to imply a relationship between these two aspects and, in most cases, evidence shows that domestic airlines obtain higher cooperation levels with HSR compared to foreign airlines. So, are these two aspects really linked to each other? Under what conditions will a domestic/international air-rail partnership exist? Which type of air-rail cooperation is more desirable from a social welfare perspective? Although some papers have qualitatively analyzed the nature and the implications of air-rail intermodal agreements (Chiambaretto and Decker, 2012; European Commission, 2006), our paper is the first attempt to answer these questions analytically.

The contribution of this paper is mainly two-fold. On the one hand, it is the first theoretical paper to discuss the variety of air-rail partnerships. With the growing popularity of this intermodal arrangement around the world, due to reasons such as airport capacity constraint and environmental concerns, it would be of great benefit to the academia as well as the transport industry to better understand its mechanism. As a newly emerged but rapidly developing phenomenon, a large number of air-rail partnerships were formed in the past few years, which largely explains why there are not yet many existing studies on this topic. On the other hand, with a thorough welfare analysis, this paper also provides the conditions of and comparisons among various types of air-rail partnership scenarios, leading to potential policy developments. Whenever regulators find it necessary to have a careful investigation on the air-rail cooperation, possibly due to potential anti-trust issues (e.g., Jiang and Zhang, 2014), they might find this study useful as it offers a base to distinguish different types of such intermodal partnerships.

The paper is organized as follows. Section 2 sets up the basic model while Section 3 derives four different partnership scenarios and their respective equilibrium cooperation levels, profits as well as social welfare. Section 4 compares cooperation levels and social welfares across different scenarios and analyzes equilibrium market structure. Section 5 offers concluding remarks. 


\section{Model}

In this paper, we only consider a connecting market involving a domestic leg and an international leg. ${ }^{4}$ There are three companies: a domestic airline, a domestic rail operator, and a foreign airline. We assume that the domestic airline can serve both legs with its own operation, while the rail operator can only serve the domestic leg, and the foreign airline can only serve the international leg. This setting is representatively shown in Figure 1. Node 2 represents a domestic hub city that is used by the domestic airline as a gateway to the outside world, while node 1 represents a peripheral city within the country. Node 3 is an important international hub, or a collection of such international hubs, with the presence of both the domestic airline and the foreign airline. An example of this setting is as follows. The domestic airline is Air France while the foreign airline is Air China. Node 2 is Paris Charles de Gaulle, while node 3 is Beijing Capital. Node 1 represents a French peripheral city, e.g., Nantes. Both Air France and Air China may offer the connection between Paris Charles de Gaulle and Beijing Capital. However, Air China does not offer the flight connection between Paris Charles De Gaulle and Aéroport Nantes Atlantique, while Air France does. Finally, the French rail operator SNCF provides HSR connection between Paris and Nantes.

In this setting, four potential scenarios for air-rail cooperation may exist. First, when no intermodal partnership is established, the domestic airline will be a monopoly in the connecting market, offering air-air connecting service. Second, the foreign airline cooperates with the rail operator to provide air-rail connecting service as a competing product to the air-air connecting service offered by the domestic airline. Third, the domestic airline forms a partnership with the rail operator and the resulting air-rail connecting service replaces the air-air connecting service. And fourth, both airlines form partnerships with the HSR operator and compete with their respective air-rail connecting services. We

\footnotetext{
${ }^{4}$ This is different from papers that also study the two non-stop markets in a simple three-node network (e.g. Jiang and Zhang, 2014). If factors, such as economies of traffic density which link the non-stop markets with the connecting market, are taken into account, the results will be different. However, in this paper, we do not attempt to address all intricate issues. Instead, we aim to use the simplest possible model to serve as the first step analysis of this interesting topic.
} 
should note that the fourth scenario might not always be possible since in some exclusive arrangements the rail operator is not allowed to form a new partnership with an existing partnership in place. ${ }^{5}$ We dub the partnership formed by the foreign airline as international partnership, while the partnership formed by the domestic airline as domestic partnership. According to Chiambaretto and Decker (2012) and European Commission (2007), the international partnership can also be referred to as a "behind and beyond" agreement. In particular, the majority of intermodal agreements between air transport and HSR are of the "behind and beyond" route category, in which an airline sells (or puts its code on) a nonoffered route operated by the rail operator to provide connections with its own scheduled services. However, some intermodal agreements cover domestic partnership, where the rail operator enters into a code-share agreement with a domestic airline instead. These four scenarios within our network structure are represented in Figure 1.

$$
==\text { Insert Figure } 1==
$$

It should be noted that we assume away horizontal differentiation between air-air and airrail services but keep vertical (quality) differentiation in the model. Moreover, we do not impose a particular mechanism based on which an air-rail partnership splits its profit between the two companies. ${ }^{6}$ This is mainly due to two considerations. On the practical side, the revenue-sharing mechanism in various air-rail partnerships is case-by-case and usually not disclosed to the public. In other words, there is not enough information to support any specific way of modeling such mechanism. On the analytical side, it can be easily proven that as long as the total profit of a partnership is higher than the sum of the reservation profits of both parties, there is always a way to distribute the profit and make each party better off. Therefore, for the formation of a partnership, total profit of the partnership is more important than the distribution mechanism. In Section 4.2, we show that, as expected, how an air-rail partnership splits its profit between the two parties doesn't affect the qualitative result, which creates the foundation for a more stringent assumption when we analyze the more complicated situation where air-rail partnership is non-

\footnotetext{
${ }^{5}$ For example, there is a growing trend among airline alliances that alliance members are discouraged to code-share with non-alliance carriers, especially the members of other alliances (Jiang et al., 2015).

${ }^{6}$ It is popular, in alliance literature, to assume a particular revenue-sharing mechanism in the analysis (e.g., Jiang et al., 2015), but this paper's treatment is also common in literature. Please refer to Jiang and Zhang (2014) for an example.
} 
exclusive. In particular, we assume that the rail operator is a passive order taker that accepts all capacity requests from the airline(s), while the airline(s) would always request the formation of intermodal cooperation as long as the total profit of the partners increases. This assumption fits reality well and helps to free the paper from excessive analytical burden. $^{7}$

We assume that travellers maximize a (strictly concave) quadratic utility function as proposed by Singh and Vives (1984). This approach has been used in transport literature (e.g., Flores-Fillol and Moner-Colonques, 2007; Oum and Fu, 2007; Socorro and Viecens, 2013; D'Alfonso et al., 2015). Let $\boldsymbol{Q}$ be the total number of connecting passengers. The utility function is:

$$
U=\alpha \boldsymbol{Q}-\frac{1}{2} \boldsymbol{Q}^{2}
$$

where $\alpha$ measures the highest willingness-to-pay (WTP) for travel (i.e., the scale of demand). We assume that $\alpha$ is sufficiently large, i.e., the connecting market is large enough, so as to ensure the non-negativity of the equilibrium results. A simple linear inverse demand function can be derived from equation (1):

$$
P=\alpha-Q
$$

Here $P$ is the "full price" of the passengers, which is determined by the ticket price and the various nonmonetary travel costs. These costs cover travel time (e.g., en-route travel time, connecting time), and all the other factors affecting the quality of the trip such as travel convenience, including ease of check-in, security check time, baggage push, etc. We use $T_{A A}$ and $T_{A R}$ to denote the monetized travel cost of the air-air connecting service and the pre-investment air-rail connecting service for the passengers, respectively, with $T_{A A}$ and $T_{A R}$ being both positive values. The ticket price of air-air connecting service is thus:

\footnotetext{
${ }^{7}$ Rail operators are seldom initiators of any air-rail partnership. Instead of being active decision makers in such intermodal cooperation, they are closer to passive order takers, probably due to the fact that the amount of intermodal passengers is very small compared with their total operation. Most of the intermodal agreements take the form of block purchase of train capacity by the airlines. In fact, sometimes the partnership can simply be a reimbursement of rail ticket to the passengers by the airline such as in the examples of Tianjin and Shijiazhuang airports.
} 


$$
p_{A A}=P-T_{A A}
$$

For the air-rail connecting service, since investments to improve this service are allowed, the post-investment travel cost is endogenous, depending on the air-rail cooperation level $\delta$. In particular, for the passengers, the higher the cooperation level, the lower the travel cost of the air-rail connecting service. For simplicity, we assume that the monetized postinvestment travel cost of the air-rail service is a simple linear function of $\delta$ and equal to $T_{A R}-\delta$. The ticket price of an air-rail connecting service is thus also a function of $\delta$ :

$$
p_{A R}(\delta)=P-\left(T_{A R}-\delta\right)
$$

Other than the demand side, $\delta$ also has implication on the cost side for the transport operators. There is a fixed cost involved when investments to improve air-rail service are made, and it is an increasing function of the cooperation level $\delta .{ }^{8}$ In particular, we denote the fixed cost involved in any intermodal partnership as $C(\delta)$, assuming that $C(\delta)=\mu \delta^{2}$, with $\mu \geq 0$. Moreover, we assume that the unit operating costs are $c_{A}^{d}, c_{R}^{d}$ and $c_{A}^{i}$ for air service on the domestic leg, rail service on the domestic leg, and air service on the international leg, respectively.

In the following text we use $q$ and $Q$ to denote the traffic levels of air-air connecting and air-rail connecting services, and $\pi$ and $\Pi$ to denote the profits of a single transport operator and an intermodal partnership, respectively. In the first scenario, only the domestic airline offers air-air connecting service and its objective function is

$$
\pi_{1}^{D}=\left(p_{A A}-c_{A}^{d}-c_{A}^{i}\right) q_{1}^{D}
$$

The superscript $D$ denotes domestic airline and the subscript $l$ denotes scenario 1 . The social welfare function in this scenario is:

\footnotetext{
${ }^{8}$ More integrated intermodal cooperation can involve a form of code-share arrangement, in which the airline and the rail operator decide to 'share' the same train trip, and each operator assigns its own flight/train code to the train trip. In this case, the convenience of the air-rail service increases due to coordinated booking and ticketing, but it also means some costly integration of IT systems. Deeper forms of integration can take the form of coordination of through-baggage handling and other dedicated services, such as separate first- and business-class dining facilities on trains, which further increases the convenience of the air-rail service through channels like the decrease of connecting time, but the logistics cost involved in implementing these integrations dramatically increases (Chiambaretto and Decker, 2012).
} 


$$
W_{1}=\alpha q_{1}^{D}-\frac{1}{2} q_{1}^{D^{2}}-\left(T_{A A}+c_{A}^{d}+c_{A}^{i}\right) q_{1}^{D}
$$

In the second scenario, only the international air-rail partnership exists and the objective functions of the domestic airline and the international air-rail partnership are:

$$
\begin{gathered}
\pi_{2}^{D}=\left(p_{A A}-c_{A}^{d}-c_{A}^{i}\right) q_{2}^{D} \\
\Pi_{2}^{F}=\left(p_{A R}-c_{R}^{d}-c_{A}^{i}\right) Q_{2}^{F}-\mu\left(\delta_{2}\right)^{2}
\end{gathered}
$$

The superscript $F$ denotes foreign airline and the subscript 2 denotes scenario 2 . The social welfare function is ${ }^{9}$ :

$$
\begin{gathered}
W_{2}=\alpha\left(q_{2}^{D}+Q_{2}^{F}\right)-\frac{1}{2}\left(q_{2}^{D}+Q_{2}^{F}\right)^{2}-\left(T_{A A}+c_{A}^{d}+c_{A}^{i}\right) q_{2}^{D}-\left(T_{A R}+c_{R}^{d}+c_{A}^{i}\right. \\
-\delta) Q_{2}^{F}-\mu\left(\delta_{2}\right)^{2}
\end{gathered}
$$

In the third scenario, only the domestic air-rail partnership exists and the objective function of the domestic partnership is:

$$
\Pi_{3}^{D}=\left(p_{A R}-c_{R}^{d}-c_{A}^{i}\right) Q_{3}^{D}-\mu\left(\delta_{3}\right)^{2}
$$

The subscript 3 denotes scenario 3 . And the social welfare function is given by:

$$
W_{3}=\alpha Q_{3}^{D}-\frac{1}{2} Q_{3}^{D^{2}}-\left(T_{A R}+c_{R}^{d}+c_{A}^{i}-\delta\right) Q_{3}^{D}-\mu\left(\delta_{3}\right)^{2}
$$

In the last scenario where both types of partnership coexist, the objective functions of the two partnerships are:

$$
\begin{aligned}
& \Pi_{4}^{D}=\left(p_{A R}-c_{R}^{d}-c_{A}^{i}\right) Q_{4}^{D}-\mu\left(\delta_{4}^{D}\right)^{2} \\
& \Pi_{4}^{F}=\left(p_{A R}-c_{R}^{d}-c_{A}^{i}\right) Q_{4}^{F}-\mu\left(\delta_{4}^{F}\right)^{2}
\end{aligned}
$$

\footnotetext{
${ }^{9}$ Note that in this paper we consider global social welfare, i.e., we do not differentiate the profit of foreign companies and the surplus of foreign consumers from the profit of domestic companies and the surplus of domestic consumers. It might require extra attention when we discuss relevant policies, as policy makers usually care about welfare only within a country.
} 
The subscript 4 denotes scenario 4 . And the social welfare function is given by:

$$
\begin{aligned}
W_{4}=\alpha\left(Q_{4}^{D}+\right. & \left.Q_{4}^{F}\right)-\frac{1}{2}\left(Q_{4}^{D}+Q_{4}^{F}\right)^{2}-\left(T_{A R}+c_{R}^{d}+c_{A}^{i}-\delta_{4}^{D}\right) Q_{4}^{D}-\left(T_{A R}+c_{R}^{d}\right. \\
& \left.+c_{A}^{i}-\delta_{4}^{F}\right) Q_{4}^{F}-\mu\left(\delta_{4}^{D}\right)^{2}-\mu\left(\delta_{4}^{F}\right)^{2}
\end{aligned}
$$

For analytical simplicity, we normalize $T_{A A}+c_{A}^{d}+c_{A}^{i}=0$ and $T_{A R}+c_{R}^{d}+c_{A}^{i}=-t$, with $t$ being either a positive or a negative value and measuring the passengers' travel cost plus the transport operators' operating costs difference between air-air and pre-investment airrail services. In other words, $t$ captures all the original heterogeneities between air-air and air-rail connecting services before the air-rail partnership makes any investment. The larger $t$ is, the better the pre-investment air-rail service is compared with the air-air service in terms of the sum of operating costs borne by the transport operators and the monetized travel cost borne by travellers. For simplicity we will refer $t$ as the quality difference between air-air and pre-investment air-rail services in the following text, incorporating both operating costs borne by the transport operators and the travel cost borne by passengers.

We model a three-stage decision process. In the first stage, the decision depends on whether air-rail partnership is exclusive or non-exclusive. If this intermodal partnership is exclusive, the two airlines compete for the right to cooperate with the rail operator. Eventually at most one partnership can be formed, which means that only scenarios 1,2 and 3 are possible. If air-rail partnership is non-exclusive, the two airlines play a simple game structured in Table 1, where the airlines have two strategies, form a partnership with the rail operator, or do not form a partnership. The four scenarios correspond to the potential equilibrium outcomes under the game between the two players. In the second stage, the intermodal partnership(s), if any, decides (decide) on the level of cooperation. In the third stage, taking the cooperation level as given, the corresponding decision maker(s) chooses (choose) its (their) traffic level(s) to maximize profit(s). ${ }^{10}$

\footnotetext{
${ }^{10}$ We use traffic, i.e., quantity, instead of price as the decision variable, to be consistent with the mainstream literature. Brander and Zhang (1990; 1993) and Oum et al. (1993) find some empirical evidence that airlines compete in quantity. Quantity competition has been assumed, among others, in Jiang and Zhang (2014), Pels and Verhoef (2004), and Zhang and Zhang (2006).
} 


\section{Scenario Analysis}

In this section, we analyze, one by one, the equilibrium traffic and cooperation level (if any) in the four scenarios. We also investigate the equilibrium profits of the transport operators to lay a foundation for subsequent market structure analysis, as well as the social welfare levels in order to derive relevant policy implications.

\subsection{No intermodal partnership}

In the first scenario, the domestic airline is a monopoly with air-air connecting service. The equilibrium traffic and the equilibrium profit of the airline, as well as the equilibrium social welfare level are straightforward:

$$
\begin{gathered}
q_{1}^{D}=\frac{\alpha}{2} \\
\pi_{1}^{D}=\frac{\alpha^{2}}{4} \\
W_{1}=\frac{3 \alpha^{2}}{8}
\end{gathered}
$$

\subsection{International partnership only}

In the second scenario, there are two products in the market, the air-air connecting service offered by the domestic airline and the air-rail connecting service offered by the international partnership. By backward induction, we first derive the equilibrium traffic and then the equilibrium level of cooperation between the foreign airline and the HSR operator, which is:

$$
\delta_{2}=\frac{2(\alpha+2 t)}{9 \mu-4}
$$

It should be noted that second-order condition requires $\mu>4 / 9$. Plugging $\delta_{2}$ into the equilibrium traffic expressions, we have 


$$
\begin{gathered}
q_{2}^{D}=\frac{\alpha(3 \mu-2)-3 \mu t}{9 \mu-4} \\
Q_{2}^{F}=\frac{3 \mu(\alpha+2 t)}{9 \mu-4}
\end{gathered}
$$

We notice that $t$ must be within a particular range, i.e., $-\alpha / 2<t<-(2-3 \mu) \alpha / 3 \mu$, in order to have both services in place. In other words, the difference between the air-air and the pre-investment air-rail services plays a role in determining the travel products available. In particular, when the quality of the air-air service is sufficiently higher than the preinvestment quality of the air-rail service, the international partnership finds it hard to compete with the domestic airline and the scenario resembles the no partnership case. On the other hand, when the pre-investment quality of the air-rail service is sufficiently higher than the quality of the air-air service, the market will be left with the air-rail connecting service provided by the international partnership only, which, however, is not a relevant case as the domestic airline will avoid it by forming domestic air-rail partnership (see the proof of Proposition 2 in Appendix B). The equilibrium profits and social welfare level are:

$$
\begin{gathered}
\pi_{2}^{D}=\frac{[\alpha(3 \mu-2)-3 \mu t]^{2}}{(9 \mu-4)^{2}} \\
\Pi_{2}^{F}=\frac{\mu(\alpha+2 t)^{2}}{9 \mu-4} \\
W_{2}=\frac{4 \alpha^{2}\left(3-14 \mu+18 \mu^{2}\right)+4 \alpha t\left(18 \mu^{2}-5 \mu\right)+t^{2}\left(99 \mu^{2}-32 \mu\right)}{2(9 \mu-4)^{2}}
\end{gathered}
$$

\subsection{Domestic partnership only}

In the third scenario, there is only one product in the market, which is the air-rail connecting service offered by the domestic partnership. The domestic partnership decides first on the level of cooperation and then on the traffic quantity. Backward induction gives the equilibrium level of $\delta$ : 


$$
\delta_{3}=\frac{\alpha+t}{4 \mu-1}
$$

It should be noted that second-order condition requires $\mu>1 / 4$. The equilibrium traffic level is:

$$
Q_{3}^{D}=\frac{2 \mu(\alpha+t)}{4 \mu-1}
$$

while the equilibrium profit and welfare level are:

$$
\begin{gathered}
\Pi_{3}^{D}=\frac{\mu(\alpha+t)^{2}}{4 \mu-1} \\
W_{3}=\frac{\mu(6 \mu-1)(\alpha+t)^{2}}{(4 \mu-1)^{2}}
\end{gathered}
$$

\subsection{Coexistence of both partnerships}

In this scenario, both the domestic and the foreign airlines form partnerships with the rail operator. We can find the equilibrium cooperation levels of the two partnerships to be:

$$
\delta_{4}^{D}=\delta_{4}^{F}=\delta_{4}=\frac{2(\alpha+t)}{9 \mu-2}
$$

Here second-order condition requires $\mu>2 / 9$. Together with the conditions derived above, we need $\mu>4 / 9$. Plugging $\delta_{4}^{D}$ and $\delta_{4}^{F}$ into the equilibrium traffic expressions, we have

$$
Q_{4}^{D}=Q_{4}^{F}=\frac{3 \mu(\alpha+t)}{9 \mu-2}
$$

while the equilibrium profits and social welfare level are:

$$
\Pi_{4}^{D}=\Pi_{4}^{F}=\frac{\mu(9 \mu-4)(\alpha+t)^{2}}{(9 \mu-2)^{2}}
$$




$$
W_{4}=\frac{4 \mu(\alpha+t)^{2}}{9 \mu-2}
$$

\section{Equilibrium Analysis}

\subsection{Equilibrium cooperation levels}

We first focus on the comparisons of equilibrium cooperation levels. By comparing $\delta_{2}, \delta_{3}$, and $\delta_{4}$, we can obtain Proposition 1.

Proposition 1: The cooperation level when both partnerships coexist is lower than those when there is only one partnership. A single international (domestic) partnership will have a higher cooperation level than a single domestic (international) partnership when the pre-investment quality of the air-rail service is sufficiently high (low) compared with the quality of the air-air service.

The proof of Proposition 1 is given in Appendix B. This result is very interesting, as it suggests that under the same conditions a single air-rail partnership, either domestic or international, induces higher cooperation level than when competing partnerships coexist. This is because when both intermodal partnerships coexist, the two partnerships will both be better off by competing less aggressively in investment. Besides, compared with the case of two coexistent partnerships, at any level of cooperation, each partnership's output is higher in the case of single partnership and hence the benefit from cooperation is also higher, incentivizing the single partnership to achieve higher cooperation level. On the other hand, only when the pre-investment air-rail service is sufficiently good compared with the air-air connecting service, international partnership would generate a higher cooperation level than domestic partnership. This is caused by the fact that the international partnership still needs to compete with the domestic airline in Scenario 2, while the domestic partnership can enjoy monopoly status in Scenario 3, so the increase of air-rail service quality has a steeper impact on the international partnership. In other words, when the pre-investment quality of the air-rail service is low, the international partnership has lower incentive to increase this quality through investments compared with the domestic 
partnership; but when pre-investment quality of the air-rail service is high, this relationship would reverse.

\subsection{Equilibrium market structure}

Next, we discuss which of the four scenarios would be elicited as the equilibrium outcome under various conditions. Two situations will be investigated: first, the air-rail cooperation is exclusive, meaning that Scenario 4 where both partnerships coexist is not possible; second, the intermodal cooperation is non-exclusive, meaning that Scenario 4 is also included in the discussion. Proposition 2 and 3 cover the findings under these two situations, respectively.

When the air-rail partnership is exclusive, the two airlines are competing for the right to cooperate with the rail operator. In this case, the benchmark for the domestic airline in deciding whether to form partnership with the rail operator is not scenario 1 when neither of the partnerships is formed. Instead, it is scenario 2 where international partnership between the foreign airline and the rail operator is formed. Meanwhile, the reservation profit of the rail operator to get into a domestic partnership is no longer nil, since it would be able to obtain a positive profit in an international partnership. Analytically, the following relations hold. When a domestic partnership is formed, $\Pi_{3}^{D}$ is the equilibrium profit obtained by the partners, with $\theta \Pi_{3}^{D}$ being the portion of profits retained by the rail operator, with $0 \leq \theta \leq 1$, and, consequently, $(1-\theta) \Pi_{3}^{D}$ being the portion of profits retained by the domestic airline. Similarly, when an international partnership is formed, $\Pi_{2}^{F}$ is the equilibrium profit obtained by the alliance, with $\varphi \Pi_{2}^{F}$ being the portion of profits retained by the rail operator, with $0 \leq \varphi \leq 1$, and, consequently, $(1-\varphi) \Pi_{2}^{F}$ being the portion of profits retained by the foreign airline. In this occurrence, $\pi_{2}^{D}$ is the profit retained by the domestic airline. Thus, to make sure that the equilibrium partnership is domestic, the following conditions must hold: (i) $\theta \Pi_{3}^{D} \geq \varphi \Pi_{2}^{F}$, which assures that the rail's participation constraint to the domestic partnership is not violated; (ii) $(1-\theta) \Pi_{3}^{D} \geq \pi_{2}^{D}$, which assures that the domestic airline's participation constraint to the domestic partnership is not violated. Summing up relations (i) and (ii) we obtain: $(1-\theta) \Pi_{3}^{D}+\theta \Pi_{3}^{D} \geq \varphi \Pi_{2}^{F}+\pi_{2}^{D}$, that is we need to compare $\Pi_{3}^{D}-\varphi \Pi_{2}^{F}$ and $\pi_{2}^{D}$. Some simple analysis reveals a strong conclusion, which is summarized as Proposition 2. 
Proposition 2: If air-rail cooperation is exclusive, domestic partnership will appear when the pre-investment quality of the air-rail service is sufficiently high compared with the quality of the air-air service. No partnership will be formed when this quality is sufficiently low, while international partnership will exist when this quality is in an intermediate range.

The proof of Proposition 2 is given in Appendix B. Proposition 2 states that when $t$ is sufficiently large, the domestic partnership instead of the international partnership would exist. This is because it is more beneficial for the domestic airline to get involved in an airrail partnership when the pre-investment quality of the air-rail service is higher. On the one hand, it is more profitable to offer air-rail connecting service. On the other hand, the potential loss caused by the formation of a competing air-rail partnership is also larger. Furthermore, the proof of Proposition 2 suggests that the marginal cost of increasing cooperation level will also play a role. In particular, if $\mu$ is large, the value of $t$ that would make the domestic partnership to be the equilibrium market outcome is larger. This is because if a partnership is too expensive to form, the domestic airline, which can earn positive profit regardless, will have a lower incentive to get involved in an intermodal partnership than the other two players, which need a partnership in order to obtain positive profit. Of course, when $t$ is too small, the air-rail connecting service would be too inferior to compete with the air-air connecting service and it would not even be profitable for the foreign airline to offer it, leading to no air-rail partnership as the equilibrium.

When the air-rail partnership is non-exclusive, meaning that it is possible to have both domestic and international partnerships in the picture at the same time, equilibrium analysis leads to Proposition 3.

Proposition 3: If air-rail cooperation is non-exclusive, under Nash equilibrium, both partnerships coexist when the pre-investment quality of the air-rail service is sufficiently high compared with the quality of the air-air service. No partnership will be formed when this quality is very low. Only the foreign airline will form partnership with the rail operator when this quality is in an intermediate range.

The proof of Proposition 3 is given in Appendix B. It is straightforward to see why the foreign airline tends to form air-rail partnership when possible. It earns nil if staying out of 
the market, but has a chance to get positive profit by forming the partnership. Negative profit is not possible from partnership formation, as the partners can always choose zero investment which would incur no fixed cost. Understanding this, the equilibrium outcome of the game again depends solely on the incentive of the domestic airline, and Propositions 2 and 3 boil down to similar conclusions.

Propositions 2 and 3 reveal some insightful results regarding which type of air-rail cooperation will eventually emerge. The pre-investment quality of the air-rail service is crucial, which is sensible given that this factor determines whether, and by how much, the intermodal partnership is profitable. This gives lessons to policy makers or government agencies that would like to promote such intermodal cooperation. On the one hand, it cannot be taken for granted. Some preconditions may indeed be critical for the formation of an air-rail partnership. For example, even if the rail station is not physically within the hub airport, they definitely cannot be too far away and without any connection. On the other hand, to foster an air-rail partnership, the most efficient measure of regulators might be to increase the pre-investment quality of the (potential) air-rail service, such as building intermodal facilities, which will decrease the connecting time for this service. However, it should also be noted that these measures would have a stronger impact on domestic partnership instead of international partnership, making social welfare comparisons between these different scenarios particularly relevant and important.

\subsection{Social welfare comparisons}

To facilitate social welfare comparisons between different scenarios, we first obtain a lemma.

Lemma 1: The social welfare levels increase in the pre-investment quality of the air-rail service (as compared with the quality of the air-air service) in the case of a single domestic partnership and the case of both partnerships. Welfare first decreases and then increases in the quality of the air-rail service in the case of a single international partnership.

The proof of Lemma 1 is given in Appendix B. The first part of the lemma is straightforward, as in the case of a single domestic partnership and the case of both partnerships, only air-rail service is provided, so the social welfare naturally increases with 
the original (pre-investment) quality of such service. The second part of the lemma can be understood by taking a closer look at equations (21) and (22), both of which are parts of $W_{2}$. From equation (21), we can see that $\pi_{2}^{D}$ decreases in $t$, while the decreasing rate gets smaller when $t$ increases. Meanwhile, equation (22) tells us that $\Pi_{2}^{F}$ increases in $t$ with an increasing rate. When $t$ is small, its marginal effect on $\pi_{2}^{D}$ dominates that on $\Pi_{2}^{F}$, leaving a net negative effect on $W_{2}$. However, as $t$ increases, this dominance diminishes and eventually reverses. ${ }^{11}$ Intuitively, this is because in the case of a single international partnership, this partnership will offer air-rail service while the stand-alone domestic airline will offer the air-air service. The improvement of the pre-investment quality of the air-rail service has: (i) a positive impact on both the price and the traffic volume of the international partnership, which means that the increase in its profit is quadratic in this quality improvement, and (ii) a negative impact on the profit of the domestic airline that offers the competing air-air service. However, the higher the pre-investment quality of the air-rail connecting service, the lower the incentive of the international partnership to invest as heavily, so the impact on the domestic airline's profit is negative but with a decreasing rate.

Although we have 4 scenarios, from the previous sections we can infer that some comparisons are not necessary. For example, we do not need to compare scenarios 3 and 4 since we have shown that, in a setting where scenario 4 is allowed, scenario 3 will never appear. With this in mind, we can summarize Proposition 4 as follows.

Proposition 4: In terms of social welfare, a single domestic partnership is never optimal. Having no partnership is optimal only when the pre-investment quality of the air-rail service is very low compared with the quality of the air-air service. Having both partnerships is optimal when the pre-investment quality of the air-rail service is in an intermediate range and the investment cost to improve this quality is sufficiently large. Otherwise, a single international partnership is optimal.

Proposition 4 is based on a summary of the scenarios which generate the highest social welfare under different ranges of $t$ and $\mu$, as presented in Table 2. The proof of Proposition

\footnotetext{
${ }^{11}$ Consumer surplus, the other component of social welfare, monotonically increases in the pre-investment quality of the air-rail service. In other words, it does not contribute to this U-shape relationship.
} 
4 is given in Appendix B. Proposition 4 is particularly interesting when combined together with Propositions 2 and 3. After some arithmetic, we can conclude the range of $t$ which induces scenario 2 as the equilibrium is included in the range of $t$ where scenario 2 generates the highest social welfare among all the four scenarios. This result has important policy implication as it conveys that when international partnership is the only air-rail partnership in place, there is not much concern for social welfare. Unless other issues, such as environmental concerns, need to be considered, regulators can adopt a more encouraging attitude for the status quo. On the other hand, when there is only domestic partnership or when both types of partnerships coexist, the regulators might want to look closer at the situation. A more detailed and careful welfare analysis may be necessary before making any positive or negative judgment on particular air-rail cooperation cases. However, the readers should also keep in mind that this is the case when we count foreign airline's profit in the social welfare. With another setting, the conclusion might be very different.

$$
==\text { Insert Table } 2==
$$

\section{Concluding Remarks}

In this paper, we build a theoretical model to analyze different types of air-rail partnerships. We investigate one domestic airline, one foreign airline, and one rail operator in the model, where there exist two possible intermodal partnerships: a domestic partnership between the domestic airline and the rail operator, as well as an international partnership between the foreign airline and the rail operator. After a partnership is formed, air-rail connecting service will be provided and investments to improve this service are allowed at a cost. Four potential scenarios for air-rail cooperation may exist. First, no intermodal partnership is established. Second, there is only the international partnership. Third, there is only the domestic partnership. And fourth, both partnerships coexist, which is only possible when air-rail partnership is non-exclusive. We find that the cooperation level when both partnerships coexist is lower than those when only one partnership exists, while international partnership will have a higher cooperation level than domestic partnership when the pre-investment quality of the air-rail service is sufficiently high compared with the quality of the air-air connecting service with respect to passengers' travel cost plus 
transport operators' operating cost. Then we show that if air-rail cooperation is exclusive, domestic partnership will appear when the pre-investment quality of the air-rail service is high, no partnership will be formed when it is low, while international partnership will exist when it is moderate. If air-rail cooperation is non-exclusive, the coexistence of both partnerships will be the equilibrium when the pre-investment quality of the air-rail service is high, no partnership will exist when it is low, while only international partnership will emerge when it is moderate. Regarding social welfare, the case of no partnership is dominated by the other three cases when the pre-investment quality of the air-rail service is high enough. Meanwhile, the case of international partnership dominates the case of domestic partnership and the case of both partnerships if the cost of partnership investment is not very large. Otherwise, the case of international partnership is superior to the case of domestic partnership (both partnerships) if and only if the pre-investment air-rail service quality is within certain ranges.

These results have some potential policy implications. As a newly emerged phenomenon, the air-rail cooperation hasn't drawn a lot of attention yet; however, it is rapidly developing, with a large number of cases only emerged in the past few years. Meanwhile, it is a complicated issue, particularly regarding social welfare. On the one hand, it has a lot of benefits such as relieving airport congestion and alleviating environmental impacts of transportation $^{12}$. On the other hand, careful investigation is needed due to potential antitrust concern. Whenever regulators are ready to seriously evaluate air-rail cooperation cases, they will find the necessity to recognize the diversity of these cases and first sort out the driving forces behind this diversity. In that case, this framework will be very useful as it offers a base to distinguish different types of air-rail partnership, with some preliminary social welfare analysis readily available.

Some limitations exist due to the simplifications of our model. First, network effect is largely ignored in this paper. Incorporating the air as well as rail networks into the analysis would likely alter some of the conclusions, and these changes may have profound policy

\footnotetext{
${ }^{12}$ Due to severe constraints to capacity expansion, airport slots are a scarce resource. The European Commission pursues the optimal allocation and use of slots to foster competition and improve quality of air transport services (EC, 2011). In this framework, Avenali et al. (2015) study an incentive pricing mechanism to manage effectively scarce capacity at congested hubs.
} 
implications, since network is one of the defining features of transportation systems. Second, many factors are either lumped together, such as the operating costs for both modes, or still omitted from our analysis, such as the long term decisions of technology and capacity investment. Although as the first attempt to study this issue, it is necessary to simplify, while we have used a case study to obtain less restricted results to a certain sense, it would be interesting to enrich the model more in future research and study the impacts

of factors abstracted away from this paper. Furthermore, since we have analytically obtained the equilibrium outcomes for the partnership formation, another direction of future study will be to test these predictions empirically. Third, this study does not take into account environmental impacts. Some literature on the air-rail interaction has pointed out its implications on the environment, as rail service is generally believed to be more environmentally friendly than air service (e.g., Chiambaretto and Decker, 2012; D'Alfonso et al., 2015; 2016). This is particularly important for the social welfare analysis. To obtain a more thorough picture, environmental factors need to be considered.

\section{Acknowledgments}

We wish to thank the participants at the 2015 meeting of the Air Transport Research Society (ATRS) and at the 2016 conference of the International Transport Economic Association (ITEA) where earlier versions of this paper were presented. The effort of Tiziana D'Alfonso is performed in the framework of the BONVOYAGE project (From Bilbao to Oslo, intermodal mobility solutions and interfaces for people and goods, supported by an innovative communication network), funded by European Commission under the Grant Agreement no 635867. All the partners of the BONVOYAGE project team are gratefully acknowledged, for their constant and constructive cooperation and helpful suggestions. Financial support from Hong Kong Polytechnic University (code: G-UC62) is also is gratefully acknowledged. 


\section{References}

Adler, N., Pels, E., Nash, C., 2010. High-speed rail and air transport competition: Game engineering as tool for cost-benefit analysis. Transportation Research Part B: Methodological, 44(7), 812-833.

Avenali, A., D'Alfonso, T., Leporelli, C., Matteucci, G., Nastasi, A., Reverberi, P., 2015. An incentive pricing mechanism for efficient airport slot allocation in Europe. Journal of Air Transport Management, 42, 27-36.

Avenali, A., Bracaglia, V., D'Alfonso, T., Reverberi, P., 2016. Incentives to airline-High Speed Rail cooperation under hub congestion: an antitrust perspective. Mimeo.

Barrón, I., Campos, J., Gagnepain, P., Nash, C., Ulied, A., Vickerman, R., 2009. Economic analysis of high-speed rail in Europe. G. de Rus (Ed.). Fundación BBVA.

Behrens, C., Pels, E., 2012. Intermodal competition in the London-Paris passenger market: High-Speed Rail and air transport. Journal of Urban Economics, 71(3), 278-288.

Belobaba, P., Odoni, A., Barnhart, C. (Eds.), 2009. The global airline industry (Vol. 23). John Wiley \& Sons, Hoboken, United States of America.

Ben-Khedher, N., Kintanar, J., Queille, C., Stripling, W., 1998. Schedule optimization at SNCF: From conception to day of departure. Interfaces, 28(1), 6-23.

Bennett, E.M., Kemler, D. and Levin, B.T., 1957. Emotional associations with air and rail transportation. The Journal of Psychology, 43(1), 65-75.

Blainey, S., Hickford, A., Preston, J., 2012. Barriers to passenger rail use: a review of the evidence. Transportation Review, 32 (6), 675-696.

Brander, J., Zhang, A., 1990. Market conduct in the airline industry: an empirical investigation. Rand Journal of Economics. 21,567-583.

Brander, J., Zhang, A., 1993. Dynamic behaviour in the airline industry, International Journal of Industrial Organization, 11, 407-435.

Brueckner, J.K., 2001. The economics of international codesharing: An analysis of airline alliances. International Journal of Industrial Organization, 19, 1475-1498. 
Cattaneo, M., Malighetti, P., Morlotti, C., Redondi, R., 2016. Quantity price discrimination in the air transport industry: The easyJet case. Journal of Air Transport Management, 54, $1-8$.

Chiambaretto, P., 2015. Resource dependence and power-balancing operations in alliances: The role of market redefinition strategies.M@n@gement, 18(3),205-233.

Chiambaretto, P., Decker, C., 2012. Air-rail intermodal agreements: Balancing the competition and environmental effects. Journal of Air Transport Management, 23, 36-40.

D’Alfonso, T., Jiang, C., Bracaglia, V., 2015. Would competition between air transport and high-speed rail benefit environment and social welfare?. Transportation Research Part B: Methodological, 74, 118-137.

D’Alfonso, T., Jiang, C., Bracaglia, V., 2016. Air transport and high-speed rail competition: Environmental implications and mitigation strategies. Transportation Research Part A: Policy and Practice, 92, 261 - 276.

D’Alfonso, T., Malighetti, P., Redondi, R., 2011. The pricing strategy of Ryanair. Walsh, C., Airline Industry Strategies, Operations and Safety, Nova Science Publishers, Inc., Hauppauge, NY, 119-141.

Dobruszkes, F., 2011. High-speed rail and air transport competition in Western Europe: A supply-oriented perspective. Transport policy, 18(6), 870-879.

Eurocontrol, 2005. Potential airport intermodality development, M3S/ATM/MODAIR/EEC/WP2/1.1

European Commission, 2006. Air and Rail Competition and Complementarity, Brussels.

European Commission, 2007. Competition Impact of Airline Code-share Agreements, Brussels.

Flores-Fillol, R., Moner-Colonques, R., 2007. Strategic Formation of Airline Alliances. Journal of Transport Economics and Policy, 41, 427-449.

Fu, X., Zhang, A., Lei, Z., 2012. Will China's airline industry survive the entry of highspeed rail?. Research in Transportation Economics, 35(1), 13-25. 
Fu, X., Oum, T. H., Yan, J., 2014. An Analysis of Travel Demand in Japan's Intercity Market Empirical Estimation and Policy Simulation. Journal of Transport Economics and Policy, 48(1), 97-113.

Gayle, P., 2008. An Empirical Analysis of the Competitive Effects of the Delta/Continental/Northwest Codeshare Alliance. Journal of Law and Economics, 51, 743766.

Givoni, M., 2003. Evaluating aircraft and HST operating costs. Nectar Cluster 1 Workshop. New Trends in European Air Traffic eds Cederlund, K., Silbersky, U. Lund University, Lund, Sweden.

Givoni, M., Banister, D., 2006. Airline and railway integration. Transport Policy, 13(5), 386-397.

González-Savignat, M., 2004. Competition in air transport: the case of the high-speed train. Journal of Transport Economics and Policy, 38(1), 77-107.

Hultkrantz, L., 2013. A note on high-speed rail investments and travelers' value of time. Journal of Rail Transport Planning \& Management, 3(1), 14-21.

IATA (International Air Transport Association), 2006. Airline Cost Performance, Montreal, Canada.

ICCSAI Factbook, 2015. La competitività del Trasporto Aereo in Europa, BookSurge Publishing, Charleston.

Ito, H., Lee, D., 2007. Domestic Codesharing, Alliances, and Airfares in the U.S. Airline Industry. Journal of Law and Economics, 50, 355-380.

Ivaldi, M., Vibes, C., 2008. Price competition in the intercity passenger transport market: a simulation model. Journal of Transport Economics and Policy, 42(2), 225-254.

Janic, M., 2011. Assessing some social and environmental effects of transforming an airport into a real multimodal transport node. Transportation Research Part D: Transport and Environment, 16(2), 137-149. 
Jiang, C., Li, X., 2016. Low cost carrier and high-speed rail: A macroeconomic comparison between Japan and Western Europe. Research in Transportation Business \& Management, 21, 3-10.

Jiang, C., Wan, Y., D'Alfonso, T., 2015. Strategic choice of alliance membership under local competition and global networks. Journal of Transport Economics and Policy, 49(2), 316-337.

Jiang, C., Zhang, A., 2014. Effects of high-speed rail and airline cooperation under hub airport capacity constraint. Transportation Research Part B: Methodological, 60, 33-49.

Jiang, C., Zhang, A., 2016. Airline network choice and market coverage under high-speed rail competition. Transportation Research Part A: Policy and Practice, 92, 248-260.

Lohmann, G., Albers, S., Koch, B., Pavlovich, K., 2009. From hub to tourist destination An explorative study of Singapore and Dubai's aviation-based transformation. Journal of Air Transport Management, 15(5), 205-211.

Meunier, D., Quinet, E., 2012. Applications of transport economics and imperfect competition. Research in Transportation Economics, 36(1), 19-29.

O'Connell, J. F., 2011. The rise of the Arabian Gulf carriers: An insight into the business model of Emirates Airline. Journal of Air Transport Management, 17(6), 339-346.

OECD/ITF, 2014, The Economics of Investment in High-Speed Rail, ITF Round Table, No. 155, OECD Publishing. DOI: http://dx.doi.org/10.1787/9789282107751-en.

Oum, T.H., Fu, X., 2007. Air Transport Security User Charge Pricing: An Investigation of Flat per-passenger Charge vs. Ad Valorem User Charge Schemes. Transportation Research Part E: Logistics and Transportation Review, 43(3), 283-93.

Oum, T.H., Park, J., Zhang, A., 1996. Effects of airline code-sharing agreements on firm conduct and fares. Journal of Transport Economics and Policy, 30(2), 187-202.

Oum, T. H., Zhang, A., Zhang, Y., 1993. Inter-firm rivalry and firm-specific price elasticities in deregulated airline markets. Journal of Transport Economics and Policy, 171-192. 
Oxford Economics, 2014. Quantifying the economic impact of aviation in Dubai. A report for Emirates and Dubai Airports. Oxford.

Park, Y., Ha, H. K., 2006. Analysis of the impact of high-speed railroad service on air transport demand. Transportation Research Part E: Logistics and Transportation Review, 42(2), 95-104.

Pels, E, Verhoef, E.T., 2004. The economics of airport congestion pricing. Journal of Urban Economics, 55, 257-277.

Singh, N., Vives, X., 1984. Price and quantity competition in a differentiated duopoly. Rand Journal of Economics, 15(4), 546-554. SESE:

Socorro, M., Viecens, M., 2013. The effects of airline and high speed train integration. Transportation Research Part A: Policy and Practice, 49, 160-177.

Swan, W.M., Adler, N., 2006. Aircraft trip cost parameters: A function of stage length and seat capacity. Transportation Research Part E: Logistics and Transportation Review, 42(2), 105-115.

Thøgersen, J., 2006. Understanding repetitive travel mode choices in a stable context: a panel study approach. Transportation Research Part A: Policy and Practice, 40 (8), 621638.

UIC, 2013. Two billion passengers have travelled on TGV. Some symbolic thresholds for high speed rail in France. UIC eNews, 330.

Vickerman, R., 1997. High-speed rail in Europe: experience and issues for future development. The annals of regional science, 31(1), 21-38.

Wan, Y., Ha, H.-K., Yoshida, Y., Zhang, A., 2016. Airlines' reaction to high speed rail entries: Empirical study of the Northeast Asian market. Transportation Research Part A: Policy and Practice, 94, 532-557.

Wright, C., P., Groenevelt, H., Shumsky, R.A., 2010. Dynamic revenue management in airline alliances. Transportation Science, 44(1), 15-37.

Xia, W., Zhang, A., 2016a. Effects of air and high-speed rail transport integration on profits and welfare: the case of air-rail connecting time. Working paper. 
Xia, W., Zhang, A., 2016b. High-speed rail and air transport competition and cooperation: A vertical differentiation approach. Transportation Research Part B: Methodological, 94, 456-481.

Yang, H., Zhang, A., 2012. Effects of high-speed rail and air transport competition on prices, profits and welfare. Transportation Research Part B: Methodological, 46(10), 1322-1333.

Zhang, A., Zhang, Y., 2006. Airport capacity and congestion when carriers have market power. Journal of Urban Economics, 60(2), 229-247. 


\section{Appendix A: Existing Cases of Air-Rail Partnership}

\begin{tabular}{|l|l|l|}
\hline Country & Rail Company & Airline \\
\hline Canada & Via Rail & $\begin{array}{l}\text { Royal Jordanian (Jordan); Air } \\
\text { Transat; Hainan Airlines (China) }\end{array}$ \\
\hline Canada & Via Rail & Air Canada \\
\hline China & Yuehai Railway & Hainan Airlines \\
\hline China & CRH & China Eastern \\
\hline & $\begin{array}{l}\text { Heathrow } \\
\text { Express; First } \\
\text { West Trains }\end{array}$ & $\begin{array}{l}\text { British Airways, Singapore } \\
\text { Airlines (Singapore) }\end{array}$ \\
\hline UK & Southwest Trains & Flybe \\
\hline France & SNCF & Multiple airlines \\
\hline France & SNCF & Air France \\
\hline Germany & Deutsche Bahn & Lufthansa \\
\hline Germany & Deutsche Bahn & Multiple airlines \\
\hline Italy & Trenitalia & Aegean (Greek) \\
\hline Netherlands/Belgium & Thalys & KLM \\
\hline Netherlands/France/Belgium & Thalys & Jet Airways (India) \\
\hline Portugal & $\begin{array}{l}\text { Comboios de } \\
\text { Portugal }\end{array}$ & TAP Portugal \\
\hline Spain & Renfe & Avianca (Colombia) \\
\hline Switzerland & SBB & Swiss \\
\hline Taiwan & $\begin{array}{l}\text { Taiwan High } \\
\text { Speed Rail }\end{array}$ & China Airlines \\
\hline USA & Amtrak & United Airlines \\
\hline
\end{tabular}




\section{Appendix B: Proofs of Lemmas and Propositions \\ Proof of Proposition 1:}

$\delta_{2}-\delta_{4}=\mu(\alpha+t) /[(4 \mu-1)(9 \mu-2)]$. Since $\mu>4 / 9$ and $t>-\alpha / 2$, we have $4 \mu-$ $1>0,9 \mu-2>0$ as well as $\mu(\alpha+t)>0$. Therefore, $\delta_{2}-\delta_{4}>0$.

$\delta_{3}-\delta_{4}=2(2 \alpha+9 \mu t) /[(9 \mu-4)(9 \mu-2)]$. Since $\mu>4 / 9$ and $t>-\alpha / 2$, we have $9 \mu-4>0,9 \mu-2>0$ as well as $2 \alpha+9 \mu t>0$. Therefore, $\delta_{3}-\delta_{4}>0$.

Further, $\delta_{2}-\delta_{3}=[(2-\mu) \alpha+7 \mu t] /\left(4-25 \mu+36 \mu^{2}\right)$.

Since $\mu>4 / 9$, we have $4-25 \mu+36 \mu^{2}>0$ for all feasible $\mu$. In other words, $\delta_{2}-\delta_{3}$ increases in $t$. Given the other parameters, we show that as long as $t>(\mu-2) \alpha / 7 \mu$, we can conclude that $\delta_{2}-\delta_{3}>0$. It is also easy to show that $-\alpha / 2<(\mu-2) \alpha / 7 \mu<$ $-(2-3 \mu) \alpha / 3 \mu$, meaning that $(\mu-2) \alpha / 7 \mu$ is within the relevant range of $t$.

Q.E.D.

\section{Proof of Proposition 2:}

Given that $\varphi \in[0,1]$ and $\Pi_{2}^{F} \geq 0,\left(\Pi_{3}^{D}-\varphi \Pi_{2}^{F}\right)-\pi_{2}^{D}$ is decreasing in $\varphi$. When $\varphi=1$, considering all the feasible ranges, we have $\left(\Pi_{3}^{D}-\Pi_{2}^{F}\right)-\pi_{2}^{D} \geq 0$ if

$$
t>\frac{\left(14-55 \mu+45 \mu^{2}\right)-\sqrt{3\left(16-184 \mu+777 \mu^{2}-1431 \mu^{3}+972 \mu^{4}\right)}}{\mu(-37+99 \mu)} \alpha
$$

Therefore, when the above condition is satisfied, $\left(\Pi_{3}^{D}-\varphi \Pi_{2}^{F}\right)-\pi_{2}^{D} \geq 0$ always holds. In other words, only when

$$
t<\frac{\left(14-55 \mu+45 \mu^{2}\right)-\sqrt{3\left(16-184 \mu+777 \mu^{2}-1431 \mu^{3}+972 \mu^{4}\right)}}{\mu(-37+99 \mu)} \alpha
$$

$\left(\Pi_{3}^{D}-\varphi \Pi_{2}^{F}\right)-\pi_{2}^{D}<0$ would be possible.

We can also show that when $t<\left(-2 \mu+\sqrt{-\mu+4 \mu^{2}}\right) \alpha / \mu, \Pi_{3}^{D}-\pi_{1}^{D}<0$. While when $t<-\alpha / 2$, even the foreign airline has no incentive to form an air-rail partnership. Given 
that $\left(-2 \mu+\sqrt{-\mu+4 \mu^{2}}\right) \alpha / \mu<-\alpha / 2$, we can conclude that when $t<-\alpha / 2$, no air-rail partnership will be formed.

Here, we can also confirm that the case when there is no air-air connecting service but only air-rail service by the international partnership is not relevant, because

$$
\frac{\left(14-55 \mu+45 \mu^{2}\right)-\sqrt{3\left(16-184 \mu+777 \mu^{2}-1431 \mu^{3}+972 \mu^{4}\right)}}{\mu(-37+99 \mu)} \alpha<-\frac{(2-3 \mu) \alpha}{3 \mu}
$$

meaning that for the range of $t$ that would make the domestic airline cut all the air-air connecting service in Scenario 2, the equilibrium market structure is Scenario 3.

Q.E.D.

\section{Proof of Proposition 3:}

First we can show that $\mathrm{F}$ is a dominant strategy for the foreign airline, because $\Pi_{2}^{F} \geq 0$ and $\Pi_{4}^{F} \geq 0$, while $\pi_{1}^{F}=0$ and $\pi_{3}^{F}=0$.

Therefore, there are only two possibilities regarding the equilibrium.

We can show that $\pi_{2}^{D}-\Pi_{4}^{D}$ decreases in $t$ in the relevant range $t<-(2-3 \mu) \alpha / 3 \mu$. And when

$$
t<\frac{729 \mu^{4}-891 \mu^{3}+342 \mu^{2}-44 \mu-\mu^{1 / 2}(9 \mu-4)^{3 / 2}\left(27 \mu^{2}-15 \mu+2\right)}{2\left(162 \mu^{3}-99 \mu^{2}+16 \mu\right)} \alpha
$$

we have $\pi_{2}^{D}-\Pi_{4}^{D}>0$. Otherwise, $\pi_{2}^{D}-\Pi_{4}^{D}<0$.

Q.E.D.

\section{Proof of Lemma 1:}

From equations (27) and (31), we can easily find that

$$
\frac{\partial W_{3}}{\partial t}=\frac{2 \mu(6 \mu-1)(\alpha+t)}{(4 \mu-1)^{2}}>0
$$




$$
\frac{\partial W_{4}}{\partial t}=\frac{8 \mu(\alpha+t)}{9 \mu-2}>0
$$

While from equation (23), we have

$$
\frac{\partial W_{2}}{\partial t}=\frac{4 \alpha\left(18 \mu^{2}-5 \mu\right)+2\left(99 \mu^{2}-32 \mu\right) t}{2(9 \mu-4)^{2}}
$$

Therefore, when $t>-2 \alpha(18 \mu-5) /(99 \mu-32), \partial W_{2} / \partial t>0$. Since $t>-\alpha / 2$ and $-\alpha / 2<-2 \alpha(18 \mu-5) /(99 \mu-32)$ due to $\mu>4 / 9$, we have $\partial W_{2} / \partial t$ first decreases and then increases in $t$.

Q.E.D.

\section{Proof of Proposition 4:}

From equation (17) we see that $W_{1}$ is not a function of $t$, while from Lemma 1 we conclude that $W_{3}$ and $W_{4}$ increase in $t$. Therefore, there exist a

$$
t_{13}=\frac{-4 \mu(6 \mu-1)+\sqrt{6 \mu\left(96 \mu^{3}-64 \mu^{2}+14 \mu-1\right)}}{4 \mu(6 \mu-1)} \alpha
$$

with $W_{1}>W_{3}$ when $t<t_{13}$ and $W_{1}<W_{3}$ otherwise; and

$$
t_{14}=\frac{-8 \mu+\sqrt{6 \mu(9 \mu-2)}}{8 \mu} \alpha
$$

with $W_{1}>W_{4}$ when $t<t_{14}$ and $W_{1}<W_{4}$ otherwise.

From Lemma 1 we see that $W_{2}$ first decreases and then increases in $t$, the cutoff points are $-\alpha / 2$ and

$$
t_{12}=-\frac{45 \mu-8}{2(99 \mu-32)} \alpha
$$

with $W_{1}>W_{2}$ when $-\alpha / 2<t<t_{12}$ and $W_{1}<W_{2}$ otherwise. Since when $t<-\alpha / 2$, the two scenarios boil down to the same case, so we can conclude that $W_{1}>W_{2}$ when $t<$ $t_{12}$ and $W_{1}<W_{2}$ otherwise. 
We have $W_{2}-W_{3} \geq 0$ if $\mu<\mu_{23}=(9+\sqrt{17}) / 12$. When $\mu \geq \mu_{23}, W_{2}-W_{3} \geq 0$ if and only if $t \leq \underline{t_{23}}$ or $t>\overline{t_{23}}$, with

$$
\begin{aligned}
& \frac{t_{23}}{} \\
& =\frac{2\left(-11+110 \mu-289 \mu^{2}+198 \mu^{3}\right)-\sqrt{2(1-4 \mu)^{2}(4-9 \mu)^{2}\left(8-27 \mu+18 \mu^{2}\right)}}{\mu\left(19-278 \mu+612 \mu^{2}\right)} \alpha \\
& \overline{t_{23}} \\
& =\frac{2\left(-11+110 \mu-289 \mu^{2}+198 \mu^{3}\right)+\sqrt{2(1-4 \mu)^{2}(4-9 \mu)^{2}\left(8-27 \mu+18 \mu^{2}\right)}}{\mu\left(19-278 \mu+612 \mu^{2}\right)} \alpha
\end{aligned}
$$

We have $W_{2}-W_{4} \geq 0$ if $\mu<\mu_{24}=(23+\sqrt{97}) / 36$. When $\mu \geq \mu_{24}, W_{2}-W_{4} \geq 0$ if and only if $t \leq \underline{t_{24}}$ or $t>\overline{t_{24}}$, with

$$
\begin{aligned}
& \underline{t_{24}}=\frac{18 \mu\left(-6+23 \mu-18 \mu^{2}\right)+2 \sqrt{2 \mu(-2+9 \mu)(4-9 \mu)^{2}\left(6-23 \mu+18 \mu^{2}\right)}}{\mu\left(64-90 \mu-243 \mu^{2}\right)} \alpha \\
& \overline{t_{24}}=\frac{18 \mu\left(-6+23 \mu-18 \mu^{2}\right)-2 \sqrt{2 \mu(-2+9 \mu)(4-9 \mu)^{2}\left(6-23 \mu+18 \mu^{2}\right)}}{\mu\left(64-90 \mu-243 \mu^{2}\right)} \alpha
\end{aligned}
$$

We have $W_{3}-W_{4} \geq 0$ if $\mu<\mu_{34}=(11+\sqrt{41}) / 20$.

We can easily show that $t_{12}<t_{13} \gtrless t_{14}<\underline{t_{24}}<\underline{t_{23}}<\overline{t_{23}}<\overline{t_{24}}$ and $\mu_{34}<\mu_{24}<\mu_{23}$. The relationship between $t_{13}$ and $t_{14}$ depends on the level of $\mu$. But since in the range between $t_{12}$ and $\underline{t_{24}}, W_{2}$ is larger than the equilibrium social welfare levels of the other three scenarios, it is not important to dissect the details. $\mu_{34}$ also does not affect the social optimal scenario because when $\mu<\mu_{23}, W_{2}$ is larger than $W_{3}$. In other words, in the range of $\mu$ where $W_{3}>W_{4}$, we always have $W_{2}>W_{3}$.

With a combination of the comparisons above, the highest welfare levels of the four cases can be summarized in Table 2 .

Q.E.D. 


\section{Appendix C}

\section{C.1 The willingness-to-pay for the travel}

In order to estimate $\alpha_{A R}$, we have recorded daily prices (one way from XWG to DBX via CDG) for each AIR\&RAIL (TGVAir) service offered by the partnership Air France-SNCF (Emirates-SNCF) on airlines' websites every day of the week 06/08/2016-13/08/2016 for each travel class. ${ }^{13}$ Data have been observed in the slot 10:00am-11:00am. Everyday $x$ we set departure at day $x+1$. Both SNCF and hub-and-spoke airlines make use of dynamic pricing for revenue maximization and load-factor optimization (Wright et al., 2010; BenKhedher et al., 1998). It has been demonstrated that fares pattern, under dynamic pricing rules, can be approximated by a strictly increasing hyperbole until the day before departure, when the maximum fare is registered (ICCSAI Factbook, 2015). At this price, some evidence shows that 2 or 3 reservations are registered (Cattaneo et al., 2016; D'Alfonso et al., 2011). Thus, we expect that the average fare for flights/HSR rides departing the day after the observation is a good approximation of the maximum WTP of customers for such services, i.e., the reservation price at which demand tends to $0 .{ }^{14}$ We set the WTP of leisure (business) passengers being equal to the highest price charged among AIR\&RAIL's Economy and Premium Economy or TGVAir's Economy Saving, Economy Flex, Economy Flex Plus solutions (AIR\&RAIL's Business and La Premiere classes or TGVAir's Business Flex classes). We average those values using ad-hoc percentages of business and leisure passengers, i.e., $20 \%$ and $80 \%$ (data on the percentage of business/leisure passengers travelling between Strasbourg and Dubai are not available, to the best of our knowledge). These percentages may be somewhat arbitrary, but they reflect the fact that integrated management strategies pursued by airlines, airports, governments,

\footnotetext{
${ }^{13}$ We have excluded from our sample 11 TGVAir trips offered daily by Air France-SNCF involving two stops, one in CDG and one in Beyrouth, Rafic Hariri International. Among these options, 8 flights (average total travel time: $25 \mathrm{~h} 46 \mathrm{~min}$ ) involve 1 night to be spent in Beyrouth (charged to the traveller), 2 Flights (average total travel time: $42 \mathrm{~h} 38 \mathrm{~min}$ ) involve 2 nights to be spent - in Paris and in Beyrouth (charged to the traveller).

${ }^{14} \mathrm{We}$ acknowledge that these estimates may be a bit inaccurate. The observed prices reflect a situation in which three products are currently in the market at the same time: TGVAir, AIR\&RAIL via CDG, and an air-air connecting service via AMS. However, we observe that price charged for air-air connecting services are generally lower than fares charged for air-rail products. This is in line with the fact that own elasticity of demand is lower for HSR than for airlines (Ivaldi and Vibes, 2008; Meunier and Quinet, 2012; Behrens and Pels, 2012).
} 
and tourism authorities have allowed small, low-populated places like Dubai to become major international tourism destinations in addition to business plazas (Lohmann et al., 2009). ${ }^{15}$ These numbers are also in line with the average number of seats offered for first or business class on the four classes Boeing 777-300ER used by Air France (20\%) or on the three classes Airbus 380-800 used by Emirates (21\%).

The parameter $\alpha_{A A}$ represents the maximum WTP of connecting passengers travelling from Strasbourg to Dubai by means of air-air connecting service offered by Air FranceKLM (the only one-stop flight option available). In order to approximate this parameter, we have recorded daily prices (one way from SXB to DBX via AMS) for each flight offered by Air France-KLM on the airline's websites every day of the week 06/08/2016$13 / 08 / 2016$ for each travel class, and we have followed similar procedure as the one described for the estimation of $\alpha_{A R}{ }^{16}$

\section{C.2 The value of time}

Vickerman (1997) argues that it is key to consider total trip times for the analysis of intermodal competition in transport. Following Adler et al. (2010), we share this approach and $T_{A R}$ is computed by summing:

(i) access time to XWG

(ii) travel time, comprised of: in-vehicle time on the HST from XWG to CDG, connecting time at CDG, in-vehicle time on Air France's or Emirates' flights from CDG to DBX, respectively;

(iii) egress time from DBX.

\footnotetext{
${ }^{15}$ World Economic Forum has recently ranked the UAE 28th out of 140 countries in a report on travel and tourism competitiveness (Oxford Economics, 2014). Our choice also reflects the tendency of European people travelling more for leisure purpose in August, when our price are observed, rather than for business purpose.

${ }^{16}$ We have excluded from our sample air-air connecting services offered daily by Air France involving two stops, one in CDG and one in other French cities. Among these: (i) Lyon-Saint Exupéry (1 flight daily); (ii) Nice Côte d'Azur, (9 flights daily, 5 of which involve connecting from Paris Orly Airport to CDG); (iii) Toulouse-Blagnac, (6 flights daily, 4 of which involve connecting from Paris Orly Airport to CDG). All flights involving stops on Nice or Toulouse also require 1 night to be spent in the city charged to the traveller. Fares for economy class almost double the fares charged for one-stop flight in AMS. In contrast, they are $50 \%$ higher in the case of business class, and almost the same in the case of La Premiere class.
} 
Similarly, $T_{A A}$ is computed by summing: (i) access time to SXB; (ii) travel time, comprised of in-vehicle time on the air-air connecting service and connecting time at AMS; (iii) egress time from DBX.

The average in-vehicle time is $9 \mathrm{~h} 20 \mathrm{~min}$, combining the in-vehicle trip times of the domestic leg by rail and of the international leg by airplane, while it is $7 \mathrm{~h} 40 \mathrm{~min}$ for the air-air connecting service. Based on the estimation of Adler et al. (2010), access time at a train station is $30 \mathrm{~min}$, egress time from an airport is $1 \mathrm{~h}$, and connecting time at the hub is $1 \mathrm{~h} 30 \mathrm{~min}$. If the air-rail product is selected, we assume that connecting time at the hub is $2 \mathrm{~h}$. Airport terminals and the TGV station might be distant as well as signage might be not well developed in showing direction between the two locations. Whether the air-air connecting service or a combined air-rail product is selected, we also add to the computation the airport processing time for international business (leisure) passengers, which is equal to $1 \mathrm{~h}$ (2h) (Adler et al., 2010). This time is mainly due to security checks and baggage check-in. However, if the level of cooperation between air and rail is high, baggage check-in can be made at the rail station and signaling is well developed showing connections between airport terminals and the TGV station. We assume that, in such a case, each business (leisure) traveller saves 30min in connecting time at the hub and $45 \mathrm{~min}$ ( $1 \mathrm{~h}$ $30 \mathrm{~min}$ ) in processing time (see estimation of parameter $\sigma_{\delta}$ ). If $\delta_{A R}^{j}=1$, this assumption would imply that airport processing time becomes $15 \mathrm{~min}$ (30min) for business (leisure) passengers ${ }^{17}$ and connection at the hub is as smooth as the one involved in the air-air connecting service (i.e., connecting time at the airport is $1 \mathrm{~h} 30 \mathrm{~min}$ as in the case of a airair connecting service).

We calculate the value of time taking into account the difference between business and leisure travellers. According to González-Savignat (2004), the value of travel time is 55 eur $/ h$ (37 eur $/ h$ ) for business (leisure) travellers. We use these values to monetize the sum of in-vehicle time and time spent in connection. The value of business travellers' access time is $22 \mathrm{eur} / \mathrm{h}$, while this data is not reported for leisure travellers. We set it equal to $10 \mathrm{eur} / \mathrm{h}$. We use these values to monetize access/egress time and processing time.

\footnotetext{
${ }^{17}$ For instance, only the time required for the security checks at the airport is counted and baggage check-in at rail station is assumed to require $0 \mathrm{~h}$ (see Adler et al., 2010).
} 
While maintaining the same proportions observed for business passengers $(22 / 55)$ would have predicted a value equal to $14.8 \mathrm{eur} / \mathrm{h}$, our choice reflects the fact that business passengers place a higher value on their access time since they want to use more (travel) time for work than for other activities (Hultkrantz, 2013). We average the resulting values, taking into account the percentage of business and leisure travellers. Parameters to estimate monetized travel time are described in Table 6.

$$
==\text { Insert Table } 6==
$$

\section{C.3 The parameter $\boldsymbol{\beta}_{A R}$}

Ivaldi and Vibes (2008), Meunier and Quinet (2012), Behrens and Pels (2012) find that own elasticity of demand is lower for HSR than for airlines. For instance, according to Behrens and Pels (2012) based on a case study on the London-Paris route in 2009, if the fare of the Eurostar alternative (Air France, taking off from London Heathrow) decreases by $1 \%$, market share would increase $0.07 \%(0.33 \%)$ and $0.15 \%(0.54 \%)$ in the business and leisure market, respectively. If we set the own elasticity of demand for airlines equal to 1 , previous evidence suggests $\beta_{A R}>1$. We set $\beta_{A R}=1.2$ (but different simulations, eventually, can be run setting varying values of $\beta_{A R}$ to examine the marginal impact of this parameter on our findings).

\section{C.4 The parameter $\sigma_{\delta}$}

To the best of our knowledge, we are not aware of estimates regarding the monetary value that customers attach to the quality of air-rail connection within the cooperation between the airline and the rail operator. In order to have a reasonable estimate, we rely on monetary values that travellers attach to time. In particular, we assume that within the "High" level of cooperation, according to the definition proposed by Chiambaretto and Decker (2012), baggage check-in can be made at the rail station and signage is well developed showing connections between airport terminals and the TGV station. We assume that, in such a case, each business (leisure) traveller saves 30min in connecting time at the hub and $45 \mathrm{~min}$ (1h $30 \mathrm{~min})$ in processing time, for a total of $1 \mathrm{~h} 15 \mathrm{~min}(2 \mathrm{~h})$. We average the resulting values according to the percentage of business and leisure passengers. According to this framework, for instance, a leisure passenger would gain $2 \cdot 37 \cdot 0.5=37$ eur, if the level of cooperation embedded in the selected air-rail product is approximately "Moderate", e.g., 
$\delta_{A R}^{j}=0.5$, or 74eur if the level of cooperation embedded in the selected air-rail products is maximum, $\delta_{A R}^{j}=1$.

\section{C.5 The parameter $\gamma$}

The parameter $\gamma$ measures the degree of horizontal differentiation between air-air connecting services and air-rail products. Besides the travel time, different factors may affect mode substitutability: emotional associations may play a role (Bennett et al., 1957), as well as cultural/personal mode preferences (IATA, 2006). Habit may also form a significant barrier to mode shift, as past mode choices are a strong predictor of current mode choice (Blainey et al., 2012; Thøgersen, 2006). Larger values of $\gamma$ indicate more substitutable services: $\gamma$ is zero when the two modes are independent and it is equal to one when they are perfect substitutes. Following Jiang and Zhang (2014) and D'Alfonso et al. (2015), based on Behrens and Pels (2012) on the London-Paris route, we set $\gamma=0.71$. In general, literature suggests that, while $\gamma$ may cover a wide range of values due to the diversity of market characteristics, it is more likely to be relatively large (Ivaldi and Vibes, 2008; Meunier and Quinet, 2012). We note that different simulations, eventually, can be run setting varying values of $\gamma$ to examine the marginal impact of this parameter on our findings.

\section{C.6 Costs}

On the cost side, $c_{A}^{i}$ is the variable operating cost - per passenger - that Air France (Emirates) uses to operate the air transport service on the international leg from CDG to DBX, while $c_{R}^{d}$ is the variable operating cost - per passenger - that SNCF uses to operate rail service on the domestic leg from XWG to CDG.

Let us first focus on air transport. Swan and Adler (2006) found that great circle distance, $D$, and the number of seats on an aircraft, $S$, are the two main factors affecting aircraft trip costs. Two market-based equations were developed based on average length of haul, which incorporate aircraft size. Equation $C=\$ 0.0115(D+2200)(S+211)$ provides the cost function per flight for long haul markets (more than 5,000 kilometers), which can be used to model the cost function on the international market served by Air France and Emirates. Dollar values in these equations have been multiplied by 1.1 in order to translate the dollar 
values into euros at 2001 prices. The reference great circle distance is $D=5246 \mathrm{~km}$ between $\mathrm{CDG}$ and DBX. The reference number of seats on an aircraft is $S=385$ (average number, given $S \in\{303,298,322\}$ on the four classes Boeing 777-300ER used by Air France and $S \in\{517,489\}$ on the three classes Airbus 380-800 used by Emirates). We derive the level of airline operating costs per-flight, 56,138€/flight, that is, on average, $145.8 € /$ seat.

We note that, eventually, different cost structures can be modeled for the domestic and the international carrier in order to examine the impact of cost differentials on our findings. For instance, Emirates enjoys significantly lower operating costs than its competitors; labor costs are estimated at $18 \%$ of its expenditure compared to roughly $30 \%$ for European and North American carriers. Reasons are varied, but an important factor is the availability of cheap guest workers: ground handling, maintenance, and catering are tasks for which workers from low-wage countries, especially Pakistan and India, are employed. Accounting and IT tasks are outsourced to India and Lebanon. Regarding fuel, its proximity to oil production and refining facilities makes fuel slightly cheaper and its young fleet and latest engine technology offers an advantage (O’Connell, 2011). ${ }^{18}$

Similarly, $c_{A}^{d}$ is the operating cost per passenger that Air France supports to operate the air transport service on the international leg from CDG to AMS. We assume that $c_{A}^{i}$ does not change, since the route distance from AMS to DBX is nearly equivalent $(D=5246 \mathrm{~km})$ and the type of aircraft used is similar (Boeing 777/200). Following Swan and Adler (2006), equation $C=\$ 0.019(D+722)(S+104)$ provides the cost function per flight for short haul markets (less than 5,000 kilometers), which can be used to model the cost function on the domestic market served by Air France. The reference great circle distance is $D=450 \mathrm{~km}$ between CDG and AMS. The reference number of seats on an aircraft is $S=75$ (on the Embrarer used by Air France or HOP). We derive the level of airline variable costs per-flight, $4,384 € /$ flight, that is, on average, 58.4€/seat.

\footnotetext{
${ }^{18}$ Bulk orders and skilled manoeuvring between Airbus and Boeing allow the company to achieve volume discounts. For example, in response to the 18-month delay in the Airbus A380 programme, EK cancelled an order of 10 A340-600 and replaced it with B777-300ER, a move supporting Boeing and punishing Airbus. At the same time, Emirates announced orders of up to 100 long-haul aircraft for the B787 and the A350XWB, highlighting its strong negotiating position (Lohmann, 2009).
} 
We now turn to HSR. We estimate the operating costs per-seat. Givoni (2003) provides an estimation of HSR total operating costs for available seat kilometers (ASK), that is $0.094 € / A S K$. The length of the route is $450 \mathrm{~km}$, therefore the total operating costs are $42.3 € /$ seat (vs $58.4 € /$ seat for the provision of the air service on the same short-haul leg). We confirm some evidence suggested by literature and airlines' consultation (Eurocontrol, 2005): the reduction of operating costs (substitution of feeder flights with cheaper rail services) in order to increase profitability is one of the main drivers of intermodality development for airlines. ${ }^{19}$

As for the approximation of the fixed cost for the investments to improve the air-rail service, a rough estimation of this cost is $C\left(\delta_{A R}^{j}\right)=\mu \cdot\left(\delta_{A R}^{j}\right)^{2}$. Existence of an interior solution and the satisfaction of second order conditions when a domestic partnership holds requires $\mu>12,042$ eur. Similarly, existence of an interior solution and the satisfaction of second order conditions when an international (both) partnership (partnerships) holds (hold) require $\mu>10,760$ eur $(\mu>10,286$ eur $)$.

We note some facts provided by Eurocontrol (2005) which reports interviews with the Brand Partnership Manager at Thalys International - the rail operator managed by SNCF (62\%), SNCB/NMBS (28\%), and Deutsche Bahn (10\%) - and the Intermodal Transport Project Manager at Lufthansa, about the nature of investments performed for the implementation of the intermodal agreements. It is confirmed that, in case of high level of cooperation, investments relate to: (i) the coordination of baggage check-in/check-out process; and, (ii) the coordination of IT systems for product distribution. Assuming it is reasonable to include a portion of general and administrative costs for the implementation of the partnership (including advertising and publicity expenses), based on Belobaba et al. (2009), the cost items, as percentage of the total airline operating cost supported, include:

(i) traffic servicing costs of processing passengers, baggage, and cargo at airports: $7.1 \%$ (including labor costs);

\footnotetext{
${ }^{19}$ All estimates assume $100 \%$ load factor, but variable load factor can be easily included in the simulation changing accordingly the cost per seat.
} 
(ii) promotion and sales costs associated with airline reservations centers and ticket offices, including travel agency commissions and distribution system fees: 6.3\% (including labor costs);

(iii) general and administrative expenses (including advertising and publicity expenses) that are truly general to the airline or those that cannot be associated to a particular activity: $5.9 \%$ (including labor costs).

If we consider as a cost basis, given our case study, the level of airline operating costs perflight in the long haul market, i.e., 56,138€/flight, we derive that mentioned cost items are, respectively, 3,985€/flight, 3,537€/flight, and 3,312€/flight.

Lower bound for $\mu$ appears quite reasonable, if compared to expenses - for one international flight - related to ticket integration, baggage handling, and advertising. We do not claim to provide a basis for any empirical estimation of the fixed cost function for the implementation of the intermodal agreements, but our proposal reflects the fact that $C^{\prime}\left(\delta_{A R}^{j}\right)>0$, i.e., it becomes increasingly more costly to increase the level of partnership due to the coordination in baggage handling and integrated ticketing. The following equation can also be manipulated to allow for variability in the fixed cost for the cooperation investment of the international versus domestic partnership, i.e., $C_{\text {Air France }}\left(\delta_{A R}^{j}\right)$ and $C_{\text {Emirates }}\left(\delta_{A R}^{j}\right)$ are modeled. For instance, one may want to see how findings would change if the international partnership is more costly than the domestic one due to higher transaction costs. 


\section{List of Tables and Figures}

Table 1 Game structure when partnerships are non-exclusive

\begin{tabular}{|c|c|c|}
\hline Foreign Airline & Form & Not Form \\
\hline Domestic Airline & & \\
\hline Form & Scenario 4 & Scenario 3 \\
\hline Not Form & Scenario 2 & Scenario 1 \\
\hline
\end{tabular}

Table 2 Social optimal scenarios under different ranges of $t$ and $\mu$

\begin{tabular}{|c|c|c|c|c|c|c|}
\hline & $t<t_{12}$ & $\begin{array}{l}t_{12}<t \\
<\underline{t_{24}}\end{array}$ & $\frac{t_{24}}{<t_{23}}<t$ & $\frac{t_{23}<t}{<\overline{t_{23}}}$ & $\begin{array}{l}\overline{t_{23}}<t \\
<\overline{t_{24}}\end{array}$ & $t>\overline{t_{24}}$ \\
\hline$\mu<\mu_{24}$ & Scenario 1 & Scenario 2 & Scenario 2 & Scenario 2 & Scenario 2 & Scenario 2 \\
\hline$\mu_{24}<\mu<\mu_{23}$ & Scenario 1 & Scenario 2 & Scenario 4 & Scenario 4 & Scenario 4 & Scenario 2 \\
\hline$\mu>\mu_{23}$ & Scenario 1 & Scenario 2 & Scenario 4 & Scenario 4 & Scenario 4 & Scenario 2 \\
\hline
\end{tabular}

Note: The exact expressions of $t_{12}, \underline{t_{24}}, \underline{t_{23}}, \overline{t_{23}}, \overline{t_{24}}, \mu_{24}$ and $\mu_{23}$ are given in the proof of Proposition 4.

Table 3 AIR\&RAIL and TGVAir options for the market XWG-DBX

\begin{tabular}{ccc}
\hline XWG-CDG (dep/arr) & Connection (h:min) & CDG-DBX (dep/arr) \\
9:57am-12:01pm & $01: 54$ & $1: 55 \mathrm{pm}-10: 55 \mathrm{pm}$ \\
6:05am-7:56am & $05: 59$ & $1: 55 \mathrm{pm}-10: 55 \mathrm{pm}$ \\
\hline
\end{tabular}

AIR\&RAIL options offered by the partnership Air France-SNCF in the market XWG-DBX

\begin{tabular}{ccc}
\hline XWG-CDG (dep/arr) & Connection (h:min) & CDG-DBX (dep/arr) \\
9:46am-12:17pm & $03: 18$ & $3.35 \mathrm{pm}(+1)-0: 20(+1)$ \\
2:24pm-5:03pm & $04: 47$ & $9: 50 \mathrm{pm}-6: 30 \mathrm{am}(+1)$ \\
9:46am-12:17pm & $09: 33$ & $9: 50 \mathrm{pm}-6: 30 \mathrm{am}(+1)$ \\
\hline
\end{tabular}

TGVAir options offered by the partnership Emirates-SNCF in the market XWG-DBX 
Table 4 Reference parameters in the connecting market XWG-CDG under Scenario 4

\begin{tabular}{lll}
\hline Demand & & \\
WTP & $\alpha_{A R}$ & 3354 eur \\
Value of travel time & $T_{A R}$ & $499.13 \mathrm{eur}$ \\
Quality of air-rail connection & $\delta_{A R}^{j}$ & $(0,1]$ \\
$\begin{array}{l}\text { Value of the quality improvement due } \\
\text { to an increment in cooperation level }\end{array}$ & $\sigma_{\delta}$ & $21.5 \mathrm{eur}$ \\
$\quad \begin{array}{l}\text { Price sensitivity of demand } \\
\text { Supply }\end{array}$ & $\beta_{A R}$ & 1.2 \\
$\begin{array}{l}\text { Cost for the provision of air services in } \\
\text { the international leg }\end{array}$ & $c_{A}^{i} \cdot Q_{A R}^{d}$ & $145.8 \mathrm{eur} \cdot Q_{A R}^{d}$ \\
$\begin{array}{l}\text { Cost for the provision of rail services in } \\
\text { the domestic leg }\end{array}$ & $c_{R}^{d} \cdot Q_{A R}^{d}$ & $42.3 \mathrm{eur} \cdot Q_{A R}^{d}$ \\
$\begin{array}{l}\text { Cost for the implementation of the } \\
\text { partnership } j\end{array}$ & $C\left(\delta_{A R}^{j}\right)$ & $\mu \cdot\left(\delta_{A R}^{j}\right)^{2}$ \\
\hline
\end{tabular}

Table 5 Reference parameters in the connecting market XWG-CDG under hypothetical Scenario 2

\begin{tabular}{llll}
\hline Demand & & \\
WTP & $\alpha_{A A}$ & 2774 eur \\
Value of travel time & $T_{A A}$ & 417.37 eur \\
Degree of substitutability between & $\gamma$ & 0.71 \\
air-air and air-rail products & & \\
Supply & $\begin{array}{l}\text { Cost for the provision of air services } \\
\text { in the domestic leg }\end{array}$ & $c_{A}^{d} \cdot q_{A A}^{d}$ & $58.4 \mathrm{eur} \cdot q_{A A}^{d}$ \\
\hline
\end{tabular}


Table 6 Passengers travel times

\begin{tabular}{|c|c|c|}
\hline \multirow{2}{*}{$\begin{array}{l}\text { \% Business Passengers } \\
\text { \% Leisure Passengers }\end{array}$} & \multicolumn{2}{|c|}{$20 \%$} \\
\hline & \multicolumn{2}{|c|}{$80 \%$} \\
\hline Value of time (eur/min) & Leisure & Business \\
\hline Travel & 0.62 & 0.92 \\
\hline Access/Processing & 0.17 & 0.37 \\
\hline \multicolumn{3}{|l|}{ Time (min) } \\
\hline Access time rail station $(\mathrm{A})$ & \multicolumn{2}{|c|}{30} \\
\hline Access time airport (B) & \multicolumn{2}{|c|}{60} \\
\hline $\begin{array}{l}\text { Processing time at hub airport }(\mathrm{C}) \\
\text { In-vehicle time air-air connecting service } \\
\text { (D) }\end{array}$ & \multicolumn{2}{|c|}{460} \\
\hline In-vehicle time air-rail product $(\mathrm{E})$ & \multicolumn{2}{|c|}{560} \\
\hline Connecting time airport $(\mathrm{F})$ & & \\
\hline Air-air connecting service & \multicolumn{2}{|c|}{90} \\
\hline Air-rail product & \multicolumn{2}{|c|}{120} \\
\hline \multicolumn{3}{|l|}{ Total access time $(\mathrm{G})$} \\
\hline Air-air connecting service $(B+C)$ & 240 & 180 \\
\hline Air-rail product $(\mathrm{A}+\mathrm{C})$ & 210 & 150 \\
\hline \multicolumn{3}{|l|}{ Total travel time (I) } \\
\hline Air-air connecting service $(\mathrm{D}+\mathrm{F})$ & 550 & 550 \\
\hline Air-rail product $(\mathrm{E}+\mathrm{F})$ & 680 & 680 \\
\hline \multicolumn{3}{|l|}{ Total trip time $(\mathrm{L}=\mathrm{G}+\mathrm{I})$} \\
\hline Air-air connecting service & 790 & 730 \\
\hline$(\%$ in vehicle $)$ & $(58.2)$ & (63) \\
\hline Air-rail product & 890 & 830 \\
\hline (\% in vehicle) & $(62.9)$ & $(67.5)$ \\
\hline Saving in total trip time $(\mathrm{M})$ & $120 \cdot \delta_{A R}^{j}$ & $75 \cdot \delta_{A R}^{j}$ \\
\hline \multicolumn{3}{|l|}{ If $\delta_{A R}^{j}=1$ in air-rail product } \\
\hline Total trip time air-rail (L-M) & 770 & 755 \\
\hline (\% in vehicle $)$ & $(72.72)$ & $(74.2)$ \\
\hline
\end{tabular}


Figure 1 The network structure and air-rail partnership scenarios

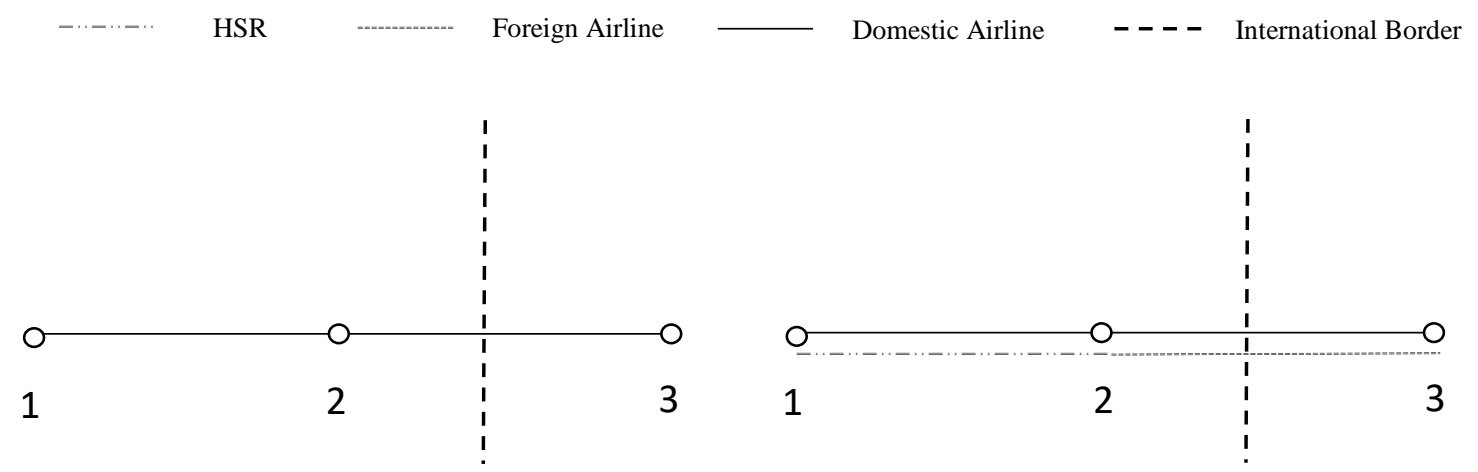

Scenario 1

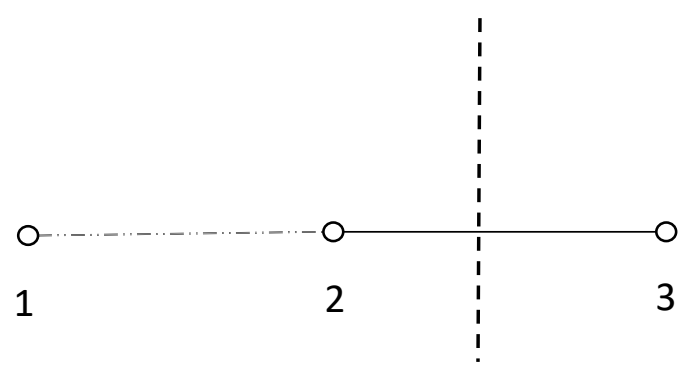

Scenario 3
Scenario 2

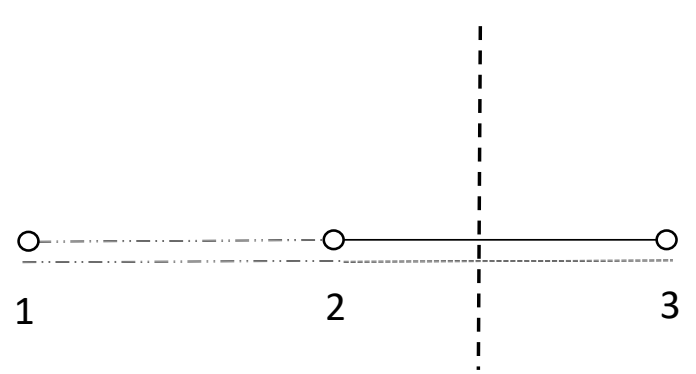

Scenario 4 
Figure 2 The TGV network in France

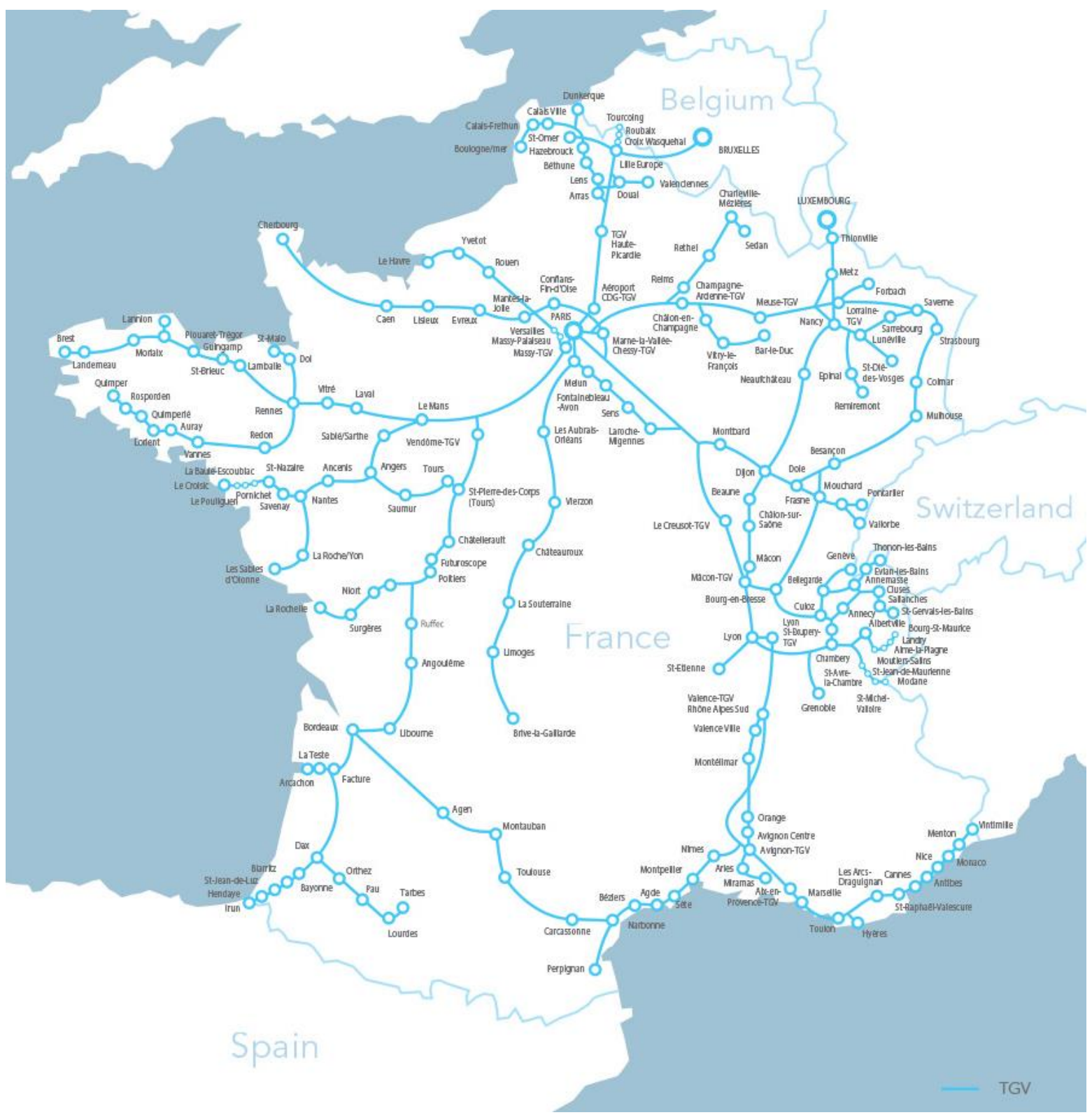

Source: http://tgv.be.voyages-sncf.com/en/carte-network-tgv 
Figure 3 Plot of $\delta$ vs. $\mu$ for the three scenarios together

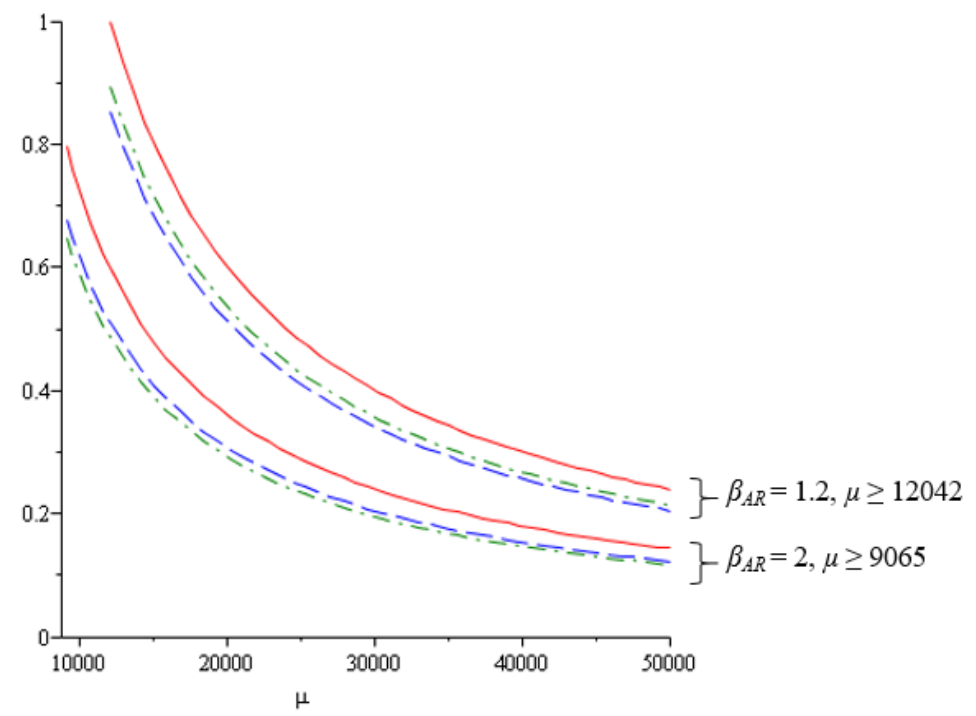

(The two numbers, 12042 and 9065, are the lowest feasible value of $\mu$ for the case of $\beta_{A R}=1.2$ and $\beta_{A R}=2$ respectively; solid $=$ domestic, dashdot $=$ international, dash $=$ coexistence)

Figure 4 Plot of $\delta$ vs. $\beta$ and $\delta$ vs. $\mu$ for the three scenarios together

\begin{tabular}{|l|l|}
\hline (a) $\delta$ vs. $\beta_{A R}: \mu=20000, \gamma=0.71$ & (b) $\delta$ vs. $\beta_{A R}: \mu=20000, \gamma=0.05$ \\
\hline &
\end{tabular}




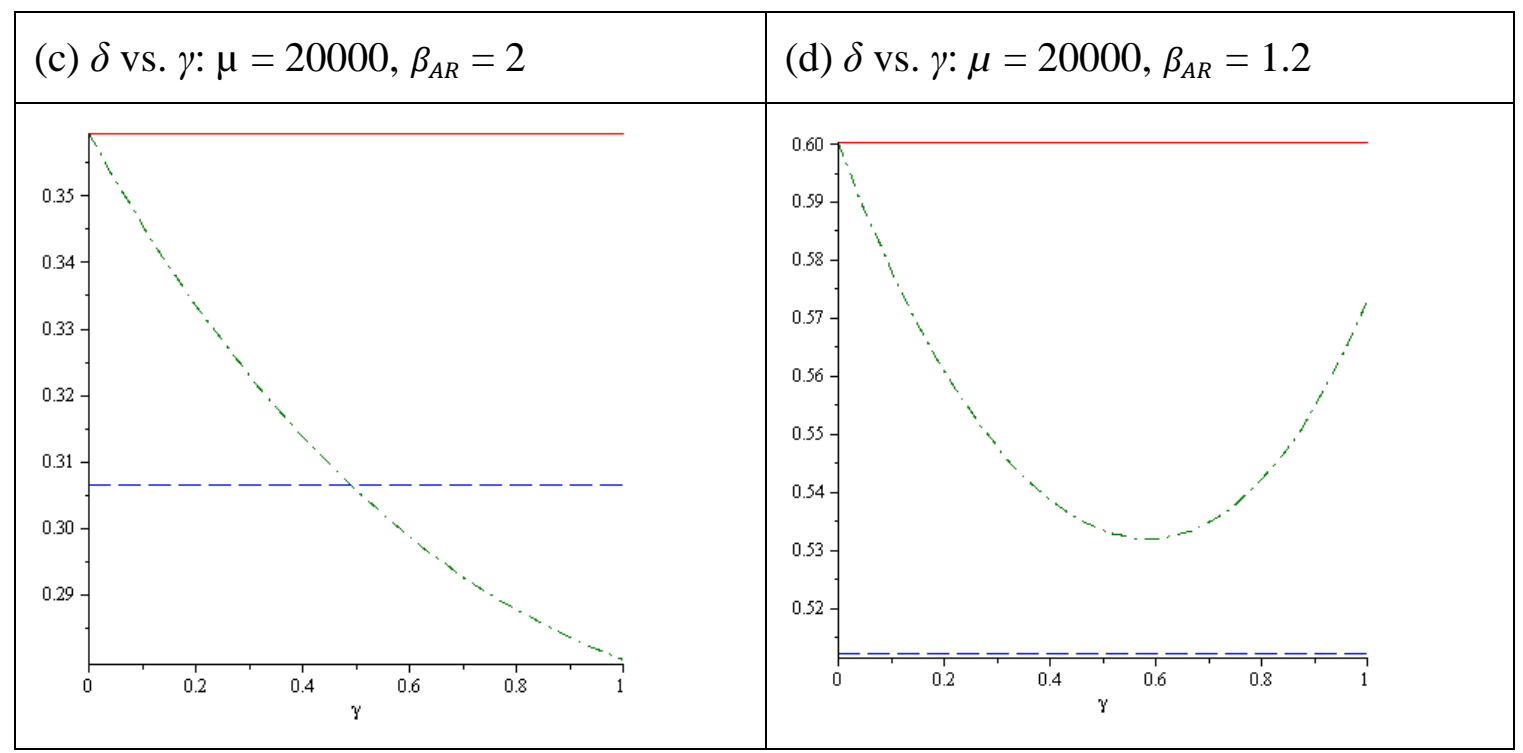

$($ solid $=$ domestic, dashdot $=$ international, dash $=$ coexistence $)$

Figure 5 Asymmetric costs and cooperation levels of domestic and international partnerships

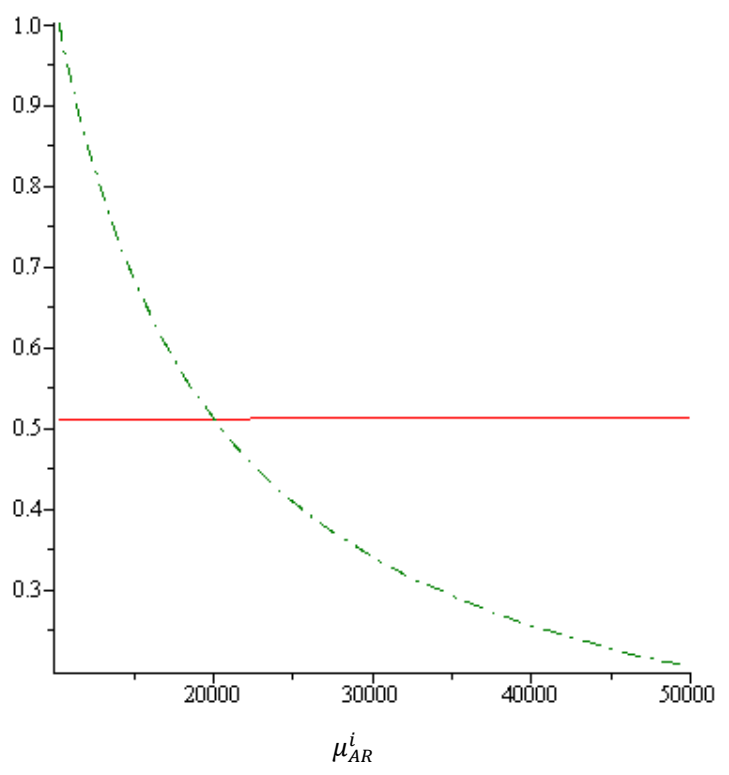

$\left(\mu_{A R}^{d}=20000,10286 \leq \mu_{A R}^{i} \leq 50000, \beta_{A R}=1.2, \gamma=0.71 ;\right.$ solid $=$ domestic, dashdot $=$ international $)$ 